\title{
Diagnóstico semiótico de un crucero peligroso en la Ciudad de México ${ }^{1}$
}

\section{Semiotic diagnosis of a dangerous intersection in Mexico City}

\author{
DOI: $10.46932 /$ sfjdv2n3-028
}

Received in: May 1st, 2021

Accepted in: Jun 30th, 2021

\author{
Santiago Osnaya Baltierra \\ Adscripción. Universidad Autónoma del Estado de México \\ Nivel de Estudios. Doctor en Ciencias y Artes para el Diseño por la Universidad Autónoma \\ Metropolitana, plantel Xochimilco \\ Líneas de investigación. Sistemas de comunicación \\ Últimas tres publicaciones: \\ Osnaya, S. (2020) "Letragrafía. Síntesis y comunicación visual” en Revista internacional \\ de Cultura Visual, ISSN 2530-4666, Madrid, España. \\ Osnaya, S. (2020) Signos urbanos. Un enfoque semiótico de la relación entre las \\ señales y los accidentes viales, ISBN 978-607-437-504-6, AM Editores, \\ México. \\ Osnaya, S. (2019) Estructura vial del Centro Histórico de la Ciudad de México, signo \\ tangible del periodo novohispano, en libro Pensamiento Novohispano 20, \\ ISBN 978-607-633-104-0, Toluca, México. \\ Función destacada: Miembro del Sistema Nacional de Investigadores nivel "C", distinción Perfil \\ PRODEP del 2013 a la fecha. \\ Correo electrónico: vosanova_24@hotmail.com
}

\section{RESUMEN}

El presente trabajo emerge en el marco del Decenio para la Seguridad Vial (DSV) 2011-2020 propuesto por la Organización de las Naciones Unidas (WHO, 2011). México fue uno de los países que se adhirió al programa, debido al alto número de siniestros de tránsito registrados anualmente. En el DSV se propone un plan de acciones para reducir el índice de accidentes viales en el mundo, las cuales están integradas en cuatro grupos (pilares) a saber, pilar uno "Gestión de la seguridad vial", pilar dos "Vías de tránsito y movilidad más segura, pilar tres "Vehículos más seguros", pilar cuatro "Usuarios de vías de tránsito más seguras" y pilar cinco "Respuestas tras los accidentes". La investigación que aquí se ofrece, obedece al pilar dos, y de manera específica, al apartado de proyectos de investigación que permitan evaluar posibles mejoras en materia de seguridad dirigida a los usuarios más vulnerables en las vialidades. En este contexto, la indagación busca identificar desde un enfoque semiótico las causas que pueden ocasionar un accidente de tránsito en un crucero vial, en el que se observe una relación directa entre los dispositivos para el control de tránsito (señales) y los peatones. Con el fin de interpretar, comprender y explicar dicho fenómeno, para con ello proponer soluciones que mitiguen la problemática.

Palabras Clave: accidente de tráfico, señales viales, semiótica

\section{ABSTRACT}

This work arises from the Decade for Road Safety (DSV) 2011-2020 proposed by the United Nations (WHO: 2011). Mexico was one of the countries where this program was introduced, because of the high

\footnotetext{
${ }^{1}$ El presente texto se deriva de una investigación mayor denominada, Signos Urbanos. La relación entre las señales y los accidentes viales (Santiago Osnaya: 2020). Este trabajo da muestra de la etapa operativa de la investigación.
} 
number of traffic accidents recorded annually. The DOV proposes a plan of actions to reduce the global road accident rate, which are integrated into four groups (pillars), pillar one "Road safety management", pillar two "Safer roads and mobility", pillar three "Safer vehicles", pillar four "Safer road users" and pillar five "Post-crash responses". Thus, the research offered here, refers to pillar two, and more specifically, to the section on research projects in order to evaluate possible improvements in the area of safety for the most vulnerable road users. In this context, the research seeks to identify from a semiotic approach the causes that can lead to a traffic accident at a crossroads, in which a direct relationship between traffic control devices (signs) and pedestrians can be observed. In order to interpret, understand and explain this phenomenon and propose solutions to mitigate the problem.

Key words: traffic accident, road signs, semiotics

\section{INTRODUCCIÓN}

En la actualidad las ciudades están trazadas desde una compleja red vial que ha evolucionado a partir de diversos aspectos socioculturales, económicos, políticos y tecnológicos. La interacción de la sociedad entre su centro y su periferia generó una traza por sectores cada vez más interrelacionados, de manera que los desplazamientos en los inicios del diseño urbano acortaron tiempo, espacio y distancia. Así, la construcción del espacio social en diferentes ciudades del mundo como Sao Paulo, Brasil, Los Ángeles, California y la Ciudad de México tienen hoy día una compleja red de trayectorias en su intensa gama de comunicaciones y transportes. En el caso de esta última -y de manera muy especial, la demarcación del centro histórico- el tejido vial se constituye principalmente de vialidades rectas que se intersecan unas con otras formándose ángulos de noventa grados. Este tipo de diseño urbano se conoce como damero, siguiendo a Woodrow Borah (1974, p.77); después del año 1573 el uso del damero fue un plan estándar de los centros urbanos edificados por los españoles. Ésta traza urbana genera intersecciones viales que hoy en día se han convertido en puntos de riesgo para las personas, debido a que en dichos nodos se hace necesaria la movilidad de diversos usuarios. Si bien los cruceros están normados por un código vial a través de los Dispositivos para el Control de Tránsito (DCT) en el Distrito Federal (Gobierno del Distrito Federal, 2001), con el objetivo de que los trayectos sean seguros, esto no sucede así, de ahí la pertinencia de realizar una investigación al respecto para establecer la eficiencia o no de los señalamientos.

En su particular cotidianidad los usuarios, actores e interlocutores que se trasladan por las ciudades producen una movilidad vial mediante una carga importante de valores socioculturales y significados relativamente estables, es decir, los significados son susceptibles de transformación dinámica a través de la comunicación de los usuarios en las vialidades. De ahí que la construcción del sentido y el acto comunicativo de las trayectorias se forma en el contexto, en la práctica de la vida cotidiana donde diversos aspectos confluyen en espacios que se suponen son apropiados para el tránsito seguro de las personas. 
Así, el espacio público es la construcción donde convergen la interacción de las relaciones sociales y su materialidad, es decir, de las infraestructuras. Los individuos producen y consumen significados mediante el acto comunicativo. Es en este sentido que las trayectorias en los espacios públicos necesitan de un estudio sobre la constitución de la relación sígnica y su significado de todos aquellos Dispositivos para el Control de Tránsito en la Ciudad de México "DCTCDMX" implicados en la movilidad de las intersecciones viales. Esta unión sintagmática de un signo con otro para producir un acto comunicativo unívoco es lo que Louis Hjelmslev (1971) tuvo a bien denominar bajo el concepto de acto solidario o sintaxis componencial (Osnaya, 2020), es decir, todos y cada uno de los DCTCDMX deben de tener una conexión lógica en el espacio vial. De ahí que la buena o mala interpretación del código vial en los cruceros por parte de los usuarios dependa, en gran medida, del uso y aplicación de cada uno de éstos, para que la movilidad de todas las personas (peatones, conductores, ciclistas, etcétera), sea armoniosa y segura. Dichas manifestaciones sociales comunicativas se analizarán desde el "campo de la semiótica" en tanto que dichos contextos sociales implican la relación de datos sensibles (signos) con un modelo conceptual determinado en toda medida por un intérprete. En palabras de Eco (1997, p.71) esto no es otra cosa que el proceso de semiosis, refiriéndose a este como es la relación de datos sensibles con el modelo conceptual que tiene el intérprete. De acuerdo con Osnaya (2020, p.95) dicho proceso puede entenderse con el siguiente ejemplo:

Una persona camina por el parque y percibe, por el sentido del oído, un canto silvestre (signo); en un primer momento de la percepción, el sujeto reconoce por este hecho (el sonido) exterior a él, la cualidad de algo (primeridad). Posteriormente, la experiencia (conocimientos previos) de esta persona le hace inferir que ese algo (objeto) puede ser hipotéticamente un canario (segundidad). En un tercer momento, el individuo investiga para verificar su hipótesis y disipar su duda. Así, observa que el ave que emite el canto tiene un plumaje de color amarillo, y por comparación con su modelo conceptual considera que en efecto se trata con toda seguridad de un canario. Es entonces cuando enmarca su percepción dentro de las leyes de la naturaleza, y por eso llega a la terceridad (interpretación de la realidad).

Es preciso aclarar, que en los "campos de interacción" (cruceros viales) se proyectan reglas, normas y convenciones de la ideología y la cultura determinada, que en nuestro caso es la cultura vial mexicana, pues en dichas intersecciones y no en otra parte es donde se refleja la valorización de los signos por parte de los actores sociales. Así, dependiendo del grado de valor, interpretación y sintaxis de cada uno de los DCTCDMX involucrados será el cumplimiento de estas normas y reglas sociales, dando pauta, quizás, a una adaptación eficaz o incluso, a la ampliación o modificación de dichas normas, que pueden bien funcionar como esquemas flexibles; en este caso se trata de los reglamentos y las normas de los hechos sociales, en tanto que cada espacio urbano tiene sus propias características.

Por los argumentos anteriores y los datos estadísticos proporcionados por el Secretariado Técnico del Consejo Nacional para la Prevención de Accidentes (CONAPRA, 2013) y la Secretaria de Seguridad 
Pública (SSP) de la Ciudad de México, se determinó qué trayectorias viales en las avenidas de la Ciudad de México eran susceptibles de investigación por su alto índice de accidentalidad. Es mediante un estudio de caso (tres cruceros con alto índice de peligrosidad en la delegación Cuauhtémoc) que se logró ver en lo empírico la constitución de los significados derivado de las relaciones sintagmáticas en relación con usos, normas y reglas establecidas en cada uno de los espacios (cruceros viales) que rigen la semántica de las señalizaciones y su aplicación o no en los cruceros que son objeto de estudio de esta investigación. Por cuestiones de extensión, el texto solamente muestra uno de los estudios realizados.

El trabajo permite reconocer los hechos viales como sucesos culturales y sociales, y a los DCT como signos dependientes a un código vial. Para la interpretación de la información se ha utilizado la teoría semiótica a través del fundamento teórico de Charles Sanders Peirce, Louis Hjelmslev y Umberto Eco, con la finalidad de analizar la función eficaz o ineficaz de las señales viales, si existe o no disfunción sintagmática de los signos ocasionada por ruido visual (natural o artificial), falta de dispositivos viales, mal uso o aplicación de los signos ocasionando que resulten fuera de la sintaxis componencial, signos sin correspondencia de interpretación carentes de toda significación. Dichas causas fueron consideradas de acuerdo con el modelo semiótico propuesto por Osnaya (2020), y que a medida que se avance en el desarrollo del texto se ira explicando.

Para dar cumplimiento a lo anterior se realizó el levantamiento de los datos in situ con el fin de analizar los diversos aspectos que son imperativos en los siniestros. De esta manera, se llevó a cabo el trabajo de campo en tres cruceros conflictivos en la Delegación Cuauhtémoc a saber, Eje Central Lázaro Cárdenas en su intersección con Dr. Río de la Loza, Eje 1 Poniente y Eje 2 Av. Manuel González, así como, Puente de Alvarado y Av. Paseo de la Reforma. Como ya se mencionó, la selección de estos objetos de estudio fue a raíz de datos estadísticos generados por la CONAPRA y la SSP. A través del informe de ambas instituciones se detectó qué cruceros tenían el mayor número de accidentes de tránsito en dónde estaban involucrados los peatones.

El desarrollo de la investigación en los sitios de estudio se realizó con un método cualitativo de los "hechos viales como sucesos sociales" y por ende de las "señales como signos viales" para comprender de qué manera la producción del significado en los contextos y nodos viales se generan e interpretan en dichos lugares. El documento da cuenta de que la investigación es del tipo hipotética-deductiva. De ahí, que la importancia de estar en campo se base en la observación, recopilación y descripción de los acontecimientos in situ para entender de manera directa los comportamientos de los actores y elementos involucrados en la movilidad de las áreas de investigación como son los peatones, automovilistas, transportistas, ambulantes, ciclistas, oficiales de tránsito, reglamento, señalamientos (DCTCDMX), etcétera. El análisis de cada uno de las personas involucradas y dispositivos nos dará la clave para entender 
mejor los “campos de interacción y significación” donde se lleva a cabo las funciones y disfunciones del código vial en sus distintos usos y aplicaciones sobre el espacio público. De esta forma, cada uno de los factores involucrados en el fenómeno de los siniestros nos orientara para dilucidar las posibles causas de los accidentes en las intersecciones viales. Además, nos permitirá contrastar el uso y aplicación de los DCTCDMX en términos de sus reglas y convenciones determinadas a través de las políticas públicas dictadas en el Manual de Dispositivos para el Control de Tránsito en Zonas Urbanas y Suburbanas del Distrito Federal (MDCTZUSDF), reflejando con ello un complejo esquema de valorización de los dispositivos viales tanto por las autoridades responsables de dicha normatividad como por parte de los actores involucrados en el acto de movilidad de los cruceros, ya sea para el cumplimiento o desacato a estas normas.

\section{OBJETO DE ESTUDIO}

La observación se llevó a cabo en tres cruceros peligrosos de la Ciudad de México ubicados en la Delegación Cuauhtémoc. Estos lugares fueron seleccionados por tener el registro más alto de siniestros en un periodo de tres años (2010-2012). Sin embargo, para cuestiones de extensión, solamente se presenta el tercer caso (Puente de Alvarado y Av. Paseo de la Reforma).

1.- $\quad$ Eje Central Lázaro Cárdenas y Dr. Rio de la Loza (41 accidentes)

2.- $\quad$ Eje 1 Poniente y Eje 2 Av. Manuel González (51 accidentes)

3.- $\quad$ Puente de Alvarado y Av. Paseo de la Reforma (45 accidentes) 
Figura 1. Ubicación de los tres espacios de investigación.

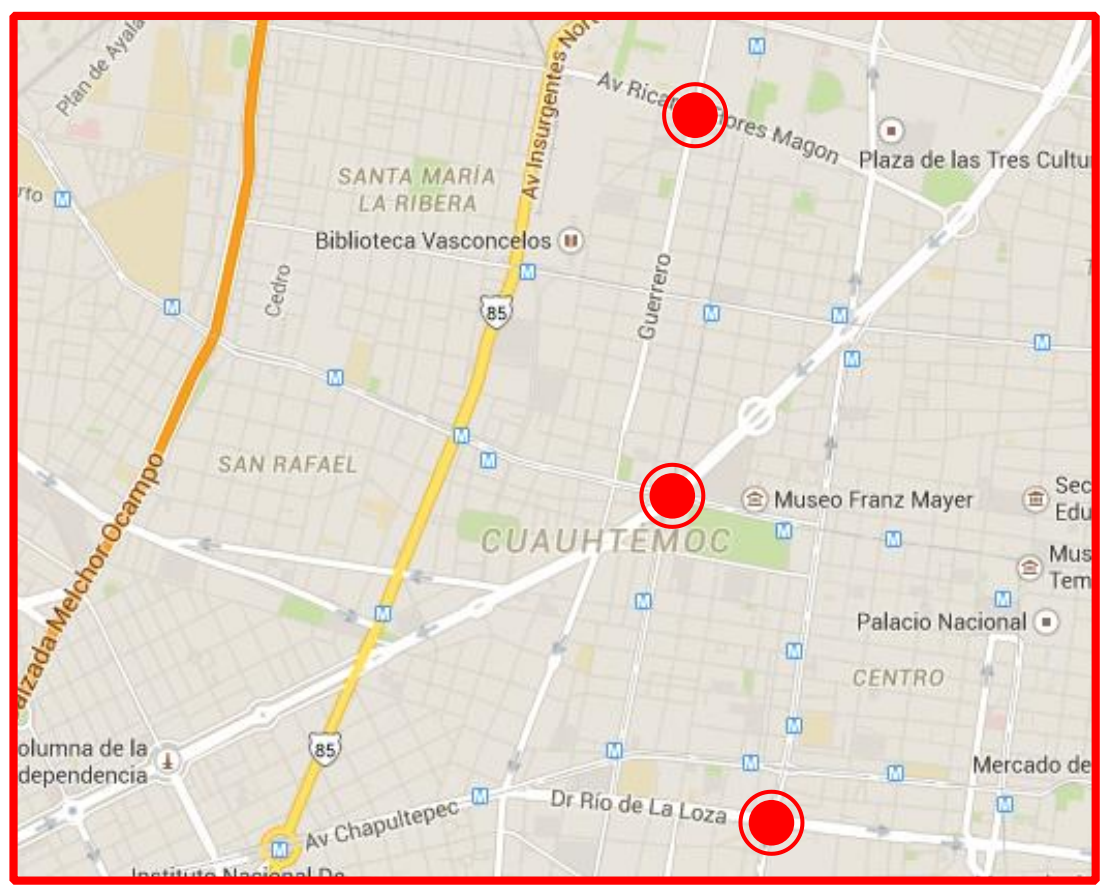

Fuente: Google maps.com.mx

\section{TÉCNICAS DE INVESTIGACIÓN}

El trabajo de campo se estructuró a partir de la siguiente pregunta de investigación, ¿En qué medida los accidentes de tránsito están relacionados con los signos viales? Para ello se tomaron como referente cuatro actores, los peatones, los automovilistas, los ciclistas y los ambulantes. Las actividades se realizaron en los meses de agosto, septiembre, octubre, noviembre del 2013, y enero, febrero, marzo, abril, mayo, junio del 2014. Aunque es preciso decir, que desde el 2012 se inició con el levantamiento y reconocimiento fotográfico de los sitios en cuestión.

En el desarrollo de la indagación se realizó el reconocimiento de campo sobre las características generales de cada crucero, a partir de las herramientas cualitativas, haciendo observación, descripción etnográfica y mapeo del espacio vial, así como entrevistas. Las técnicas de observación de campo buscan recolectar en el terreno, en forma grupal o individual, informaciones que serán analizadas posteriormente usando las técnicas de visualización. A continuación, se describen los tres tipos de herramientas en la observación participante:

- Técnicas audiovisuales

- Técnicas de entrevista y comunicación oral

- $\quad$ Técnicas de representación visual (mapeo) 


\section{TÉCNICAS AUDIOVISUALES:}

Las imágenes permiten dar cuenta de los instantes en que se están llevando a cabo los hechos, en un espacio y tiempo determinado, es decir, muestran la realidad en la que los usuarios están inmersos en la vida cotidiana. Los recursos utilizados en este rubro son mayormente mapas y fotografías.

\section{Técnicas de entrevista y comunicación oral:}

La entrevista y comunicación oral no están enfocadas tanto a la estadística, sino a asegurar la triangulación de información desde diferentes puntos de vista: perspectivas representativas de los diferentes usuarios (informantes) y la visión de la gente respecto a sus problemas cotidianos relacionados con las vialidades (cruceros). Mas adelante se ofrecen los diferentes testimonios de las personas.

\section{Técnicas de representación visual (mapeo)}

Los mapas son representaciones simplificadas de la realidad que se utilizaron en campo para obtener una representación visual, y un manejo de los datos en segmentos manejables; tienen muchas aplicaciones en la fase de diagnóstico y análisis, muchas veces, sirven como punto de partida para los procesos de desarrollo e interpretación del fenómeno vial.

\section{Proceso de investigación}

\section{Fase de gabinete}

En este apartado se analizó la bibliografía correspondiente para el análisis empírico. Se estudiaron propuestas teórico-conceptuales para un mejor abordaje de campo. Utilizando preferentemente referentes semióticos, sin embargo, también se tomaron en cuenta apoyos teóricos del tipo antropológico e histórico que abordan las sociedades urbanas en toda su complejidad.

\section{Fase de campo}

Esta fase comenzó el 01 de agosto del 2012 hasta el 30 de junio del 2014, utilizando tres días a la semana de cada mes para obtener la información requerida. Se priorizó sobre el método cualitativo, con la utilización de diversas herramientas adecuadas a las necesidades y la movilidad de los diferentes usuarios de las vías públicas. Las tareas que se realizaron fueron las siguientes:

1.- Se identificaron los señalamientos analizando las posibles interacciones como, flujo vehicular, tipología de transporte público y los trayectos de mayor afluencia para determinar los puntos rojos de cada crucero.

2.- Se observó y describió la caracterización de la movilidad peatonal haciendo una relación de la tipología de peatones, la descripción de sus comportamientos en distintas horas, el cumplimiento de la señalización vial, aplicando entrevistas cerradas y encuestas para comprender el punto de vista de estos actores. 
3.- Se realizó la caracterización de la movilidad en automovilistas y el transporte público. Se llevó a cabo la observación y la descripción de su comportamiento, se aplicó una entrevista cerrada para indagar sobre la visibilidad de las señalizaciones, si se tiene conocimiento del significado de cada señalización o al menos de la existente en cada crucero y sobre el estado actual de las señalizaciones y posibles causas de su incumplimiento.

4.- Por último, se levantó información de los ambulantes (actor clave) instalados en las avenidas para comprender el fenómeno de los accidentes viales desde su perspectiva, ya que estas personas permanecen en su lugar la mayor parte del día, siendo actores importantes que dan cuenta del día a día de la movilidad peatonal en las zonas de estudio.

El trabajo de campo se organizó logísticamente de la siguiente manera:

\begin{tabular}{|c|c|c|c|c|c|c|c|}
\hline $\begin{array}{c}\text { Puntos } \\
\text { conflic-tivos }\end{array}$ & $\begin{array}{c}\text { Gabine- } \\
\text { te }\end{array}$ & $\begin{array}{c}\text { Reconocimien } \\
- \text { to }\end{array}$ & $\begin{array}{c}\text { Observa- } \\
\text { ción } \boldsymbol{y} \\
\text { descrip- } \\
\text { ción }\end{array}$ & $\begin{array}{c}\text { Movili- } \\
\text { dad } \\
\text { peato- } \\
\text { nal }\end{array}$ & $\begin{array}{c}\text { Movilidad } \\
\text { automovilís- } \\
\text { tica }\end{array}$ & $\begin{array}{c}\text { Actores } \\
\text { clave } \\
\text { (ambulan- } \\
\text { tes) }\end{array}$ & $\begin{array}{c}\text { Día } \\
\text { s } \\
\text { to- } \\
\text { ta- } \\
\text { les }\end{array}$ \\
\hline Crucero 1 & 1 año & 3 días & 6 días & 3 días & 3 días & 3 días & $\begin{array}{c}18 \\
\text { día } \\
\text { s }\end{array}$ \\
\hline Crucero 2 & 1 año & 3 días & 6 días & 3 días & 3 días & 3 días & $\begin{array}{c}18 \\
\text { día } \\
\text { s }\end{array}$ \\
\hline Crucero 3 & 1 año & 3 días & 6 días & 3 días & 3 días & 3 días & $\begin{array}{c}18 \\
\text { día } \\
\text { s }\end{array}$ \\
\hline
\end{tabular}

Crucero 1: Eje Central Lázaro Cárdenas y Dr. Rio de la Loza

Crucero 2: Eje 1 Poniente y Eje 2 Av. Manuel González

Crucero 3: Puente de Alvarado y Av. Paseo de la Reforma

Cuadro I: Fases del proceso de investigación.

Nota. Es preciso decir que si bien el cuadro I muestra de manera general las fases del estudio etnográfico del objeto de estudio. La observación y acopio de información de los diferentes cruceros se realizó en un tiempo aproximado de diez meses comprendidos entre agosto del 2012 y noviembre del 2014. 


\section{CARACTERÍSTICAS GENERALES DE LAS TRES VIALIDADES EN LA DELEGACIÓN CUAUHTÉMOC}

La recopilación de información se realizó en los días asignados (cuadro 1) dando como resultado un mapa del espacio vial, ubicando cada DCT que se tomó como referente para priorizar señalizaciones y dispositivos tanto horizontales como verticales, estado actual de cada dispositivo vial, disfunción para comunicar las prevenciones o restricciones y trayectorias e interacciones entre peatones y automovilistas. Esto sirvió para generar las primeras preguntas de las entrevistas, ya que, la importancia de la perspectiva de los usuarios, que transitan cotidiana o parcialmente sobre la vialidad, implica entender las maneras de cómo se llevan a cabo la interrelación entre ambos actores, denotando cuestiones culturales, económicas y políticas en el contexto vial. A través de esta actividad se obtuvo un primer acercamiento a las perspectivas que se tienen sobre dichas vialidades en conflicto.

El trabajo de escritorio consistió en la revisión cartográfica del espacio público para identificar las trayectorias vehiculares y peatonales más frecuentes, así como en el análisis de las posibles interacciones entre las avenidas que confluyen en cada punto específico en cuestión. El estudio de campo sirvió para observar in situ la correlación de los actores e interlocutores que se enfrentan en el contexto determinado. Además, se identificaron las modificaciones que existen en los dispositivos viales tomando como referencia bibliografía, la Auditoría de Seguridad Vial de la Ciudad de México, el Diagnóstico Espacial de los Accidentes de Tránsito en el Distrito Federal, el Manual de Dispositivos para Control de Tránsito en Zonas Urbanas

Suburbanas del Distrito Federal, así como las diversas cartografías sobre las vialidades de transporte público elaboradas por el Gobierno de la CDMX. 


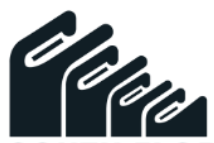

Figura 2: Intersección del espacio en cuestión.

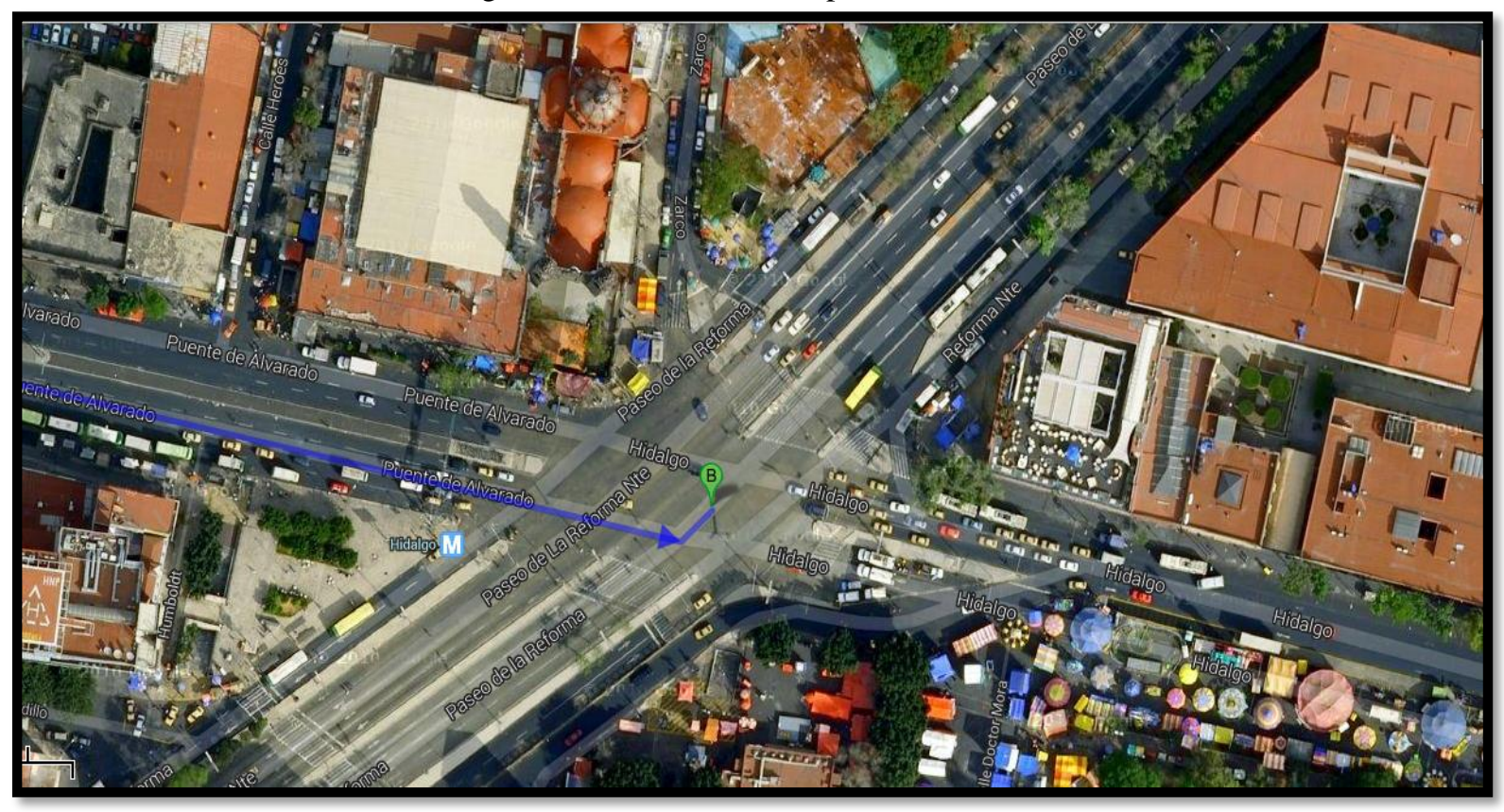

Fuente: Google maps.com.mx (2013)

Estudio III. Crucero de Av. Puente de Alvarado (Hidalgo) y Av. Paseo de la Reforma Acopio de información: agosto-octubre 2013

\section{FASE DE RECONOCIMIENTO SOBRE CARACTERÍSTICAS GENERALES.}

Presentación de la Infraestructura 
Figura 3: Flujos, trayectorias y orientaciones de vehículos Av. Puente de Alvarado (Hidalgo) y Av. Paseo de la Reforma

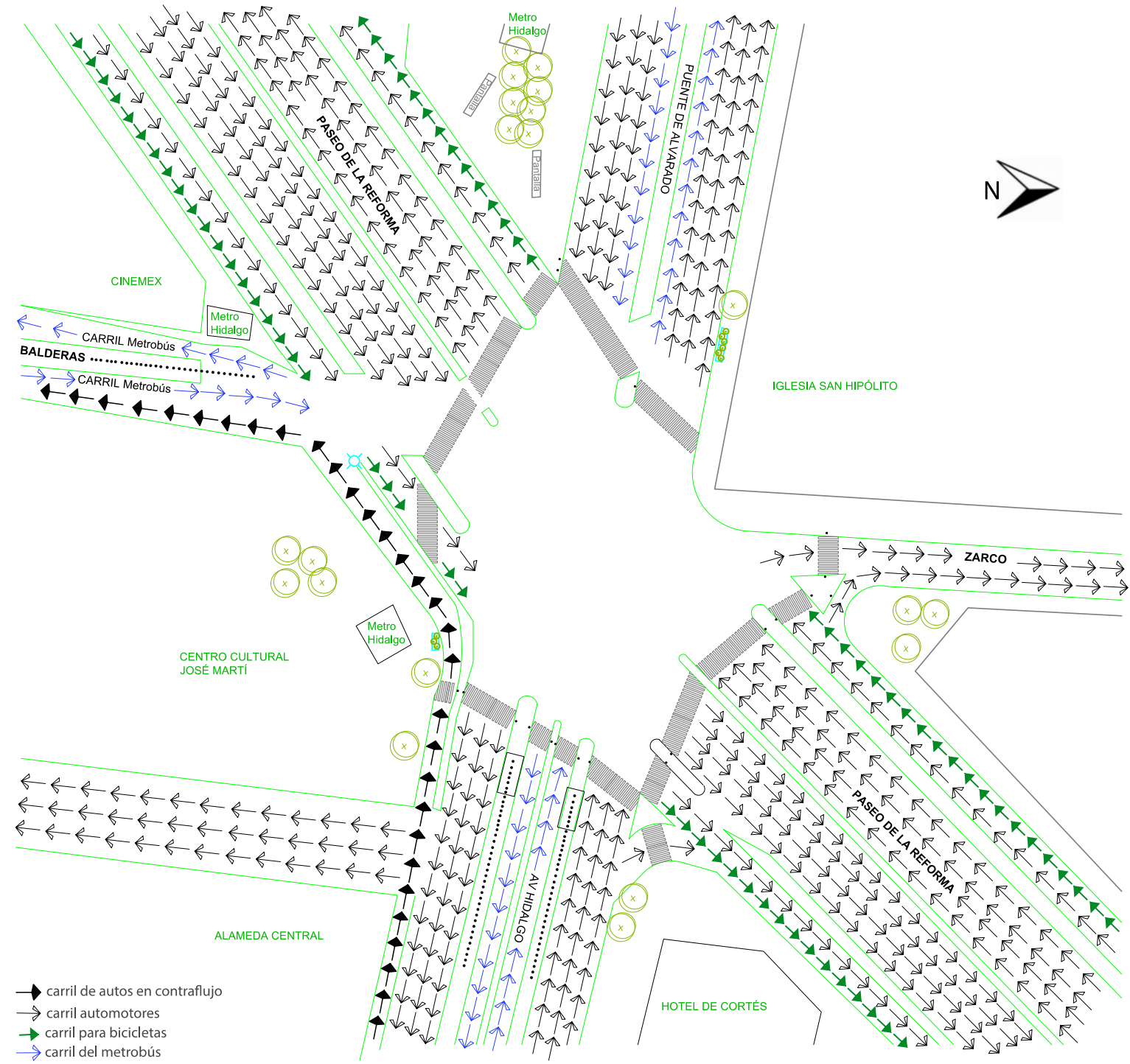

Fuente: Santiago Osnaya, 30/01/15

De los tres cruceros de estudio, este caso (III) presenta un grado de complejidad alto, debido a sus dimensiones, es decir, tiene las avenidas más amplias y el mayor número de intersecciones. Además, en dicho espacio encontramos cinco diferentes medios de movilidad a saber, bicicleta, Metrobús, transporte público privado, vehículos particulares y una línea del Metro. Son diversos los actores implicados en esta intersección lo que hace que el flujo de personas y automotores aumente, generando diversos patrones de conducta en las trayectorias. Esta situación propicia conflictos y riesgos viales, ya que se anteponen criterios basados en la experiencia, las necesidades, la edad, entre otros. Si a ello se suman las distintas anomalías que existen en la aplicación y uso de los DCT, la inseguridad de los individuos es algo que se respira en la atmósfera de este lugar.

A continuación, veremos la estructura y los distintos recorridos que existen en el crucero en mención (ver figura 3). Este cruce se conforma principalmente por dos vialidades, avenida Paseo de la 
Reforma y Puente de Alvarado (Hidalgo). Al inicio del estudio (2012), la primera trayectoria (Av. Paseo de la Reforma) se componía de doce carriles vehiculares, seis de ellos con una trayectoria de Sur a Norte, los cuales se encuentran divididos por un camellón que los separa de la siguiente manera, cuatro centrales y dos laterales, este mismo patrón se repite con las otras seis vías que se dirigen en sentido norte a sur. Sin embargo, durante la fase de estudio (2012-2014) ambos sentidos adyacentes (norte-sur / sur-norte) sufrieron una adecuación, ya que se modificó un camino vehicular en ciclopista.

Por otra parte, la calle de Avenida Hidalgo (Puente de Alvarado) está conformada por ocho carriles en la parte oeste, del lado este con dirección centro histórico, se añade un carril más, conformando un total nueve vías. Esta característica, origina tres flujos vehiculares, lo que ocasiona que el peatón se enfrente a cuatro cambios de sentido al cruce de esta vialidad. Los trayectos están dispuestos de la siguiente manera, una primera circulación tiene dirección oeste a este, sobre esta hay cuatro carriles, tres de ellos son confinados para automovilistas particulares y otro más destinado al transporte público del tipo Metrobús. Pasando avenida Reforma del lado este-sur existe un carril en contraflujo que se incorpora a la calle de Avenida Balderas. Del lado inverso, están los otros dos cursos con dirección de este a oeste, con tres carriles para particulares y uno para el Metrobús (ver figura 3).

\section{LAS SEÑALIZACIONES}

Como ya se mencionó, este crucero es uno de los más complejos en sus trayectorias viales y peatonales. La figura 3 muestra que la intersección está compuesta por dos arterias principales de gran movilidad vial (Av. Reforma y Av. Hidalgo). A primera vista parecería que la interconexión entre las dos avenidas es simple; sin embargo, la manera de cómo se da la movilidad en el día a día es complicada, por las múltiples trayectorias que en ella se generan.

Personas a pie, ciclistas, motociclistas y automovilistas generan una intrincada red de comunicación e interacción de significaciones, es decir, se producen y consumen en un mismo tiempo una amplia gama de mensajes en dicho contexto. Debido a la variedad de trayectos los usuarios se enfrentan a diversos DCT, unos dispuestos de manera correcta, otros con un uso y función que ponen en riesgo la seguridad del peatón y otros más que generan incertidumbre y confusión. Otro aspecto que caracteriza el lugar son las vallas metálicas, su uso es para controlar la conducta de las personas y con ello salvaguardar la integridad de estas. Pero esta disposición también genera riesgo, ya que los individuos prefieren evadir dichas barreras caminando por el arroyo vehicular, pues respetar las barreras implica recorrer una mayor distancia (ver figura 4). La figura 3 muestra los elementos particulares que se localizan e intervienen en la movilidad de esta intersección. Subsiguientemente el cuadro II representa el registro de los DCT aplicados en la zona. 
Figura 4

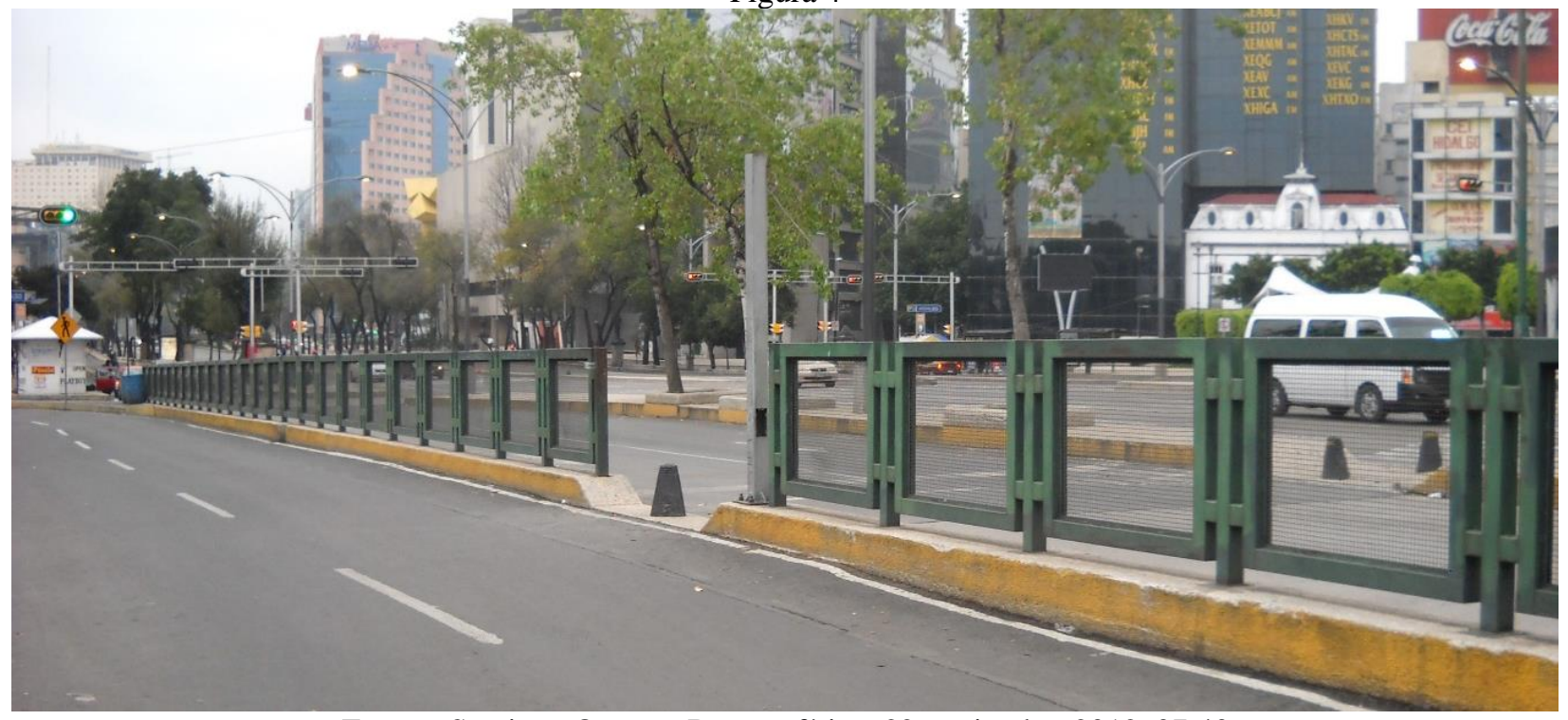

Fuente: Santiago Osnaya, Barrera física, 22 noviembre 2012, 07:40

Cuadro II

\begin{tabular}{|c|c|c|c|c|c|c|}
\hline \multicolumn{7}{|c|}{ Av. Puente de Alvarado (Hidalgo) y Av. Paseo de la Reforma } \\
\hline \multirow{5}{*}{ Informativas } & Simbología & Significado & $\begin{array}{c}\text { Hidalgo } \\
\text { este }\end{array}$ & $\begin{array}{c}\text { Hidalgo } \\
\text { oeste }\end{array}$ & $\begin{array}{c}\text { Reforma } \\
\text { sur }\end{array}$ & $\begin{array}{c}\text { Reforma } \\
\text { norte }\end{array}$ \\
\hline & $\begin{array}{l}\text { HOSPITAL INFANTIL } \\
\text { PRIVADO } 500 \mathrm{~m} \\
\end{array}$ & Confirmativa & 1 & $\mathrm{X}$ & 2 & 4 \\
\hline & $\begin{array}{c}\text { ZOCALO } \\
\text { VIADUCTO } \Rightarrow\end{array}$ & $\begin{array}{l}\text { Dirección de } \\
\text { señal elevada }\end{array}$ & 4 & $\bar{X}$ & 9 & 3 \\
\hline & [INSURGENTES] & $\begin{array}{l}\text { De nomenclatura } \\
\text { en señal baja }\end{array}$ & 4 & 2 & 2 & 2 \\
\hline & Q. & $\begin{array}{l}\text { Paso para } \\
\text { bicicletas }\end{array}$ & $\mathrm{X}$ & $\bar{X}$ & $\mathrm{X}$ & 1 \\
\hline \multirow{6}{*}{ Restrictivas } & & $\begin{array}{c}\text { Prohibido } \\
\text { estacionarse }\end{array}$ & 1 & 1 & 2 & 3 \\
\hline & & $\begin{array}{l}\text { Prohibido } \\
\text { circulación } \\
\text { motocicleta }\end{array}$ & $\mathrm{X}$ & $\mathrm{X}$ & $\mathrm{X}$ & 1 \\
\hline & $\begin{array}{l}\text { No } \\
\text { INFERII } \\
\text { INFORMAL }\end{array}$ & $\begin{array}{l}\text { Leyenda } \\
\text { restrictiva }\end{array}$ & 1 & 1 & $\mathrm{X}$ & $\mathrm{X}$ \\
\hline & & $\begin{array}{l}\text { Doble flecha de } \\
\text { circulación }\end{array}$ & $\mathrm{X}$ & $\mathrm{X}$ & $\mathrm{X}$ & 1 \\
\hline & & Prohibido retorno & \multicolumn{4}{|c|}{1} \\
\hline & & $\begin{array}{l}\text { Prohibida vuelta a } \\
\text { la izquierda }\end{array}$ & \multicolumn{4}{|c|}{2} \\
\hline Informativas & & Ciclistas & $\mathrm{X}$ & 1 & $\mathrm{X}$ & $X$ \\
\hline
\end{tabular}




\begin{tabular}{|c|c|c|c|c|c|c|}
\hline $\begin{array}{c}\text { Líneas } \\
\text { transversale } \\
\text { s } \\
\text { cebras }\end{array}$ & $\begin{array}{c}\text { Espacio permitido } \\
\text { peatonal }\end{array}$ & $\mathrm{Si}$ & $\mathrm{Si}$ & $\mathrm{Si}$ & $\mathrm{Si}$ \\
\hline $\begin{array}{c}\text { Semáforos } \\
\text { peatonales }\end{array}$ & $\mathbf{9}$ & $\begin{array}{c}\text { Regulador de } \\
\text { paso peatonal }\end{array}$ & 3 & 2 & 12 & 6 \\
\hline $\begin{array}{c}\text { Semáforos } \\
\text { vehiculares }\end{array}$ & $\begin{array}{c}\text { Regulador de } \\
\text { paso vehicular }\end{array}$ & 2 & 3 & 6 & 6 \\
\hline $\begin{array}{c}\text { Semáforo de } \\
\text { bicicleta }\end{array}$ & $\begin{array}{c}\text { Regulador del } \\
\text { paso en bicicleta }\end{array}$ & 1 & $\mathrm{X}$ & 1 & $\mathrm{X}$ \\
\hline
\end{tabular}

Fuente: Santiago Osnaya, 25/01/17

\section{CATEGORIZACIÓN DE LOS USUARIOS}

El siguiente cuadro (III) muestra la tipología de los diferentes actores que se desplazan a través de este crucero. Así mismo, la información detalla los diferentes períodos en el que las personas hacen uso de la vialidad.

Cuadro III

\begin{tabular}{|c|c|c|c|}
\hline \multirow[b]{2}{*}{ Horarios } & \multicolumn{3}{|c|}{ Usuarios } \\
\hline & Peatones & Automovilistas & Ciclistas \\
\hline $\begin{array}{l}\text { 6:00 am - 9:00 am } \\
\text { Espacio temporal } \\
\text { de gran tensión }\end{array}$ & $\begin{array}{ll}\text { 1. } & \text { Oficinistas } \\
\text { 2. } & \text { Escolares (prim/sec/prep) } \\
\text { 3. } & \text { Devotos } \\
\text { 4. } & \text { Empleados SAT }\end{array}$ & $\begin{array}{ll}\text { 1. } & \text { Taxistas } \\
\text { 2. } & \text { Transporte de carga } \\
\text { 3. } & \text { Metrobús línea } 3 \text { y } 4 \\
\text { 4. } & \text { Microbús } \\
\text { 5. } & \text { Turibús } \\
\text { 6. } & \text { Transporte carga pesada }\end{array}$ & $\begin{array}{ll}\text { 1. } & \text { Particulares } \\
\text { 2. } & \text { Ecobici } \\
\text { 3. } & \text { Motociclistas }\end{array}$ \\
\hline 9:00am - 11:00am & $\begin{array}{ll}\text { 1. } & \text { Oficinistas } \\
\text { 2. } & \text { Comerciantes } \\
\text { 3. } & \text { Empleados de SAT } \\
\text { 4. } & \text { devotos }\end{array}$ & $\begin{array}{ll}\text { 1. } & \text { Taxistas } \\
\text { 2. } & \text { Metrobús línea } 3 \text { y } 4 \\
\text { 3. } & \text { Microbús } \\
\text { 4. } & \text { Turibús } \\
\text { 5. } & \text { Particulares galería } \\
\text { 6. } & \text { Transporte carga pesada }\end{array}$ & $\begin{array}{ll}\text { 1. } & \text { Particulares } \\
\text { 2. Ecobici } \\
\text { 3. } \\
\text { Motociclistas }\end{array}$ \\
\hline 11:00am - 1:00pm & $\begin{array}{ll}\text { 1. } & \text { Escolares (primaria) } \\
\text { 2. } & \text { Comerciantes } \\
\text { 3. } & \text { Empleados SAT } \\
\text { 4. } & \text { Devotos } \\
\end{array}$ & $\begin{array}{ll}\text { 1. } & \text { Taxistas } \\
\text { 2. } & \text { Metrobus línea } 3 \text { y } 4 \\
\text { 3. } & \text { Turibús } \\
\text { 4. } & \text { Transporte carga pesada }\end{array}$ & $\begin{array}{ll}\text { 1. } & \text { Particulares } \\
\text { 2. } & \text { Ecobici } \\
\text { 3. } & \text { Motociclistas }\end{array}$ \\
\hline $\begin{array}{l}\text { 1:00 pm - 3:00 pm } \\
\text { Espacio temporal } \\
\text { de gran tensión }\end{array}$ & $\begin{array}{ll}\text { 1. } & \text { Comerciantes } \\
\text { 2. } & \text { Escolares (sec/prep) } \\
\text { 3. } & \text { Devotos } \\
\text { 4. } & \text { Empleados de SAT } \\
\text { 5. } & \text { Oficinistas }\end{array}$ & $\begin{array}{ll}\text { 1. } & \text { Taxistas } \\
\text { 2. } & \text { Metrobús línea } 3 \text { y } 4 \\
\text { 3. } & \text { Microbús } \\
\text { 4. } & \text { Turibús } \\
\text { 5. } & \text { Oficinistas } \\
\text { 7. } & \text { Transporte carga pesada }\end{array}$ & $\begin{array}{ll}\text { 1. } & \text { Particulares } \\
\text { 2. } & \text { Ecobici } \\
\text { 3. } & \text { Motociclistas }\end{array}$ \\
\hline $3: 00 \mathrm{pm}-5: 00 \mathrm{pm}$ & $\begin{array}{ll}\text { 1. } & \text { Empleados de SAT } \\
\text { 2. } & \text { Comerciantes } \\
\text { 3. } & \text { Oficinistas } \\
\text { 4. } & \text { Devotos }\end{array}$ & $\begin{array}{ll}\text { 1. } & \text { Taxistas } \\
\text { 2. } & \text { Oficinistas } \\
\text { 3. } & \text { Metrobús línea } 3 \text { y } 4 \\
\text { 4. } & \text { Microbús } \\
\text { 5. } & \text { Turibús } \\
\text { 6. } & \text { Transporte carga pesada }\end{array}$ & $\begin{array}{ll}\text { 1. } & \text { Particulares } \\
\text { 2. Ecobici } \\
\text { 3. Motociclistas }\end{array}$ \\
\hline $5: 00 \mathrm{pm}-7: 00 \mathrm{pm}$ & $\begin{array}{ll}\text { 1. } & \text { Empleados de SAT } \\
\text { 2. } & \text { Escolares (primaria) } \\
\text { 3. } & \text { Oficinistas } \\
\text { 4. } & \text { Comerciantes } \\
\end{array}$ & $\begin{array}{ll}\text { 1. } & \text { Taxistas } \\
\text { 2. } & \text { Oficinistas } \\
\text { 3. } & \text { Metrobús línea } 3 \text { y } 4 \\
\text { 4. } & \text { Microbús } \\
\end{array}$ & $\begin{array}{ll}\text { 1. } & \text { Particulares } \\
\text { 2. } & \text { Ecobici } \\
\text { 3. } & \text { Motociclistas }\end{array}$ \\
\hline
\end{tabular}




\begin{tabular}{|l|l|l|l|}
\hline & & $\begin{array}{l}\text { 5. Turibús } \\
\text { 6. Transporte carga pesada }\end{array}$ & \\
\hline & 1. Comerciantes & 1. Taxistas & 1. Particulares \\
& 2. Oficinistas & 2. Metrobús línea 3 y 4 & 2. Ecobici \\
7:00 pm $-9: 00 \mathrm{pm}$ & 3. Devotos & 3. Microbús & 3. Motociclistas \\
& & 4. Turibús & \\
& & 5. Particulares galerías & \\
\hline
\end{tabular}

\section{DESCRIPCIÓN DEL CONTEXTO VIAL}

Las trayectorias vehiculares fueron trazadas en un mapa en físico (ver figura 3). También se identificaron los diversos elementos que conforman este espacio público (cuadro II); en este campo de interacción los peatones han generado rutas con un alto porcentaje de riesgo, así fue como se detectaron cinco focos rojos que existen en esta vialidad (ver figura 5). Los cinco sitios conflictivos se encuentran distribuidos de la siguiente manera, tres en Av. Hidalgo, dos en su parte este y uno del lado oeste. Los otros dos están sobre Av. Reforma, localizados en su lado sur.

De acuerdo con la información contenida en el cuadro III, los flujos de movilidad se registran en proporciones similares durante el periodo de tiempo comprendido entre 6:00 am y 9:00 pm. Todos los puntos reflejan un alto índice de circulación, ello debido a que en este sitio confluyen cinco tipos de transporte a saber, Metrobús, Metro (línea azul), ciclopista, transporte público privado, automotores de carga y particulares. Además, la zona está conformada por oficinas públicas y de gobierno, establecimientos comerciales, sitios turísticos y culturales (museos, casa de cultura, parques y jardines), lugares históricos, entre otros. Como se observa es un área de mucha demanda por la gran diversidad de usos y medios de traslado. Este nodo de alto grado de complejidad contiene trece intersecciones que son necesarias analizar para observar y registrar las diversas tensiones generadas entre las personas a pie y los automovilistas. En los párrafos subsecuentes se describirán los trayectos de mayor uso peatonal. 
Figura 5

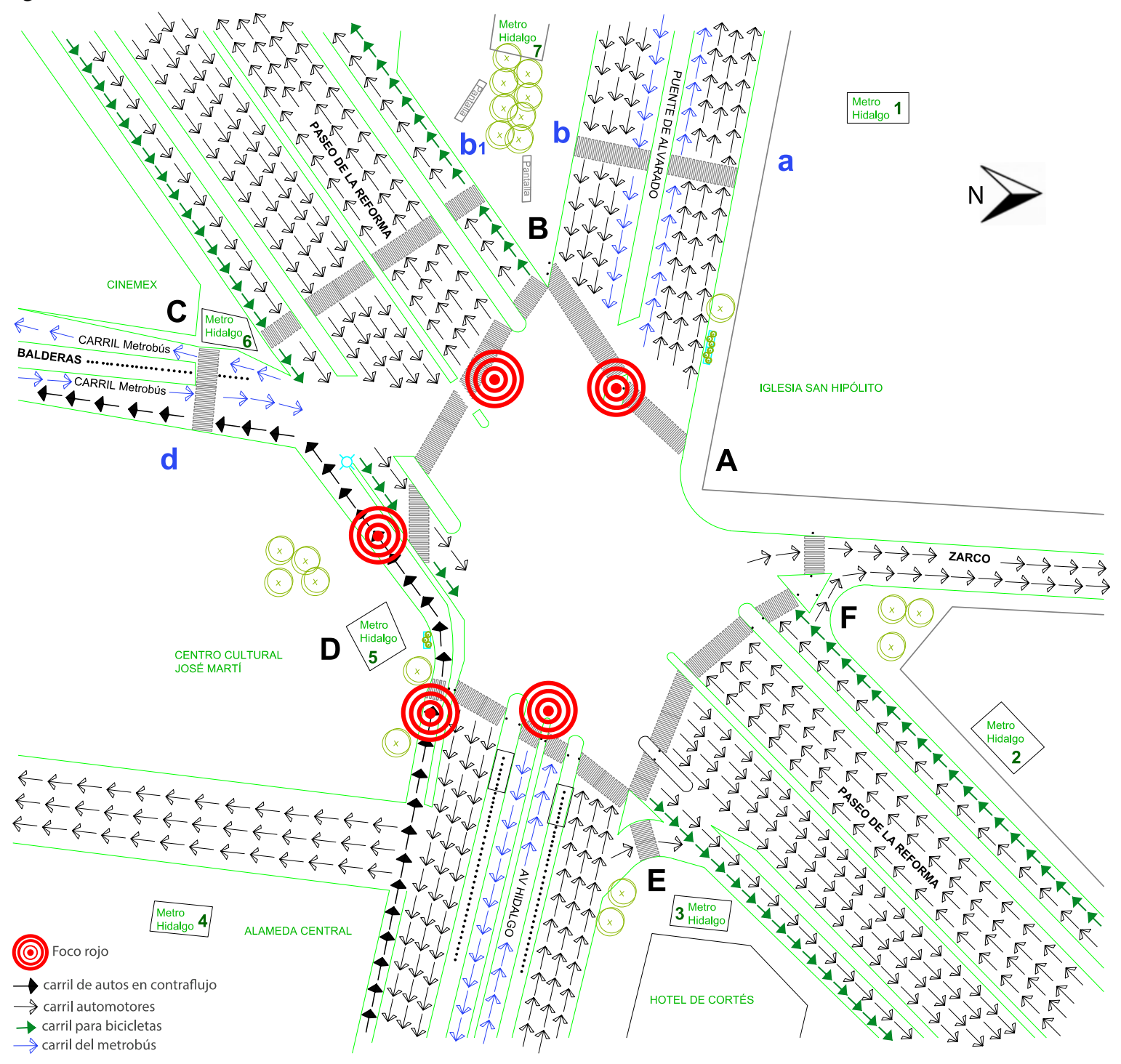

Fuente: Santiago Osnaya, focos rojos, 01/04/2016

Tomando como referencia la figura 5, señalaremos los recorridos peatonales que con mayor frecuencia son utilizados. De manera primordial es preciso decir que los usuarios utilizan dos tipos de rutas para dirigirse al mismo sitio, que bien podríamos definir como trayectos formales e informales. Los primeros son aquellos que han sido caracterizados por los funcionarios correspondientes a través de los DCT y los segundos, aunque suelen representar mayor riesgo, deben su existencia a los propios usuarios quienes por cuestiones de distancia y tiempo hacen uso de estos. También es importante remarcar que los desplazamientos están marcados en función de los distintos accesos al sistema de transporte colectivo Metro (línea 2).

Así, tenemos que las personas que salen por el acceso 1 del Metro Hidalgo (mh) suelen tomar las direcciones, a-b y a-A-F-E-D. La opción a-b, es para aquellas personas que se dirigen a tomar el autobús público en b1 o para dirigirse a las diferentes oficinas del centro de la ciudad que se encuentran sobre Av. 
Juárez y Av. Balderas. Los que optan por a-A-F-E-D, usualmente van a las oficinas del SAT (Servicios de Administración Tributaria), la Alameda Central, Teatro Hidalgo, museos ubicados sobre Avenida Hidalgo o las calles comerciales de Artículo 123 y Victoria. También la salida $3 \mathrm{mh}$ se utiliza para estas mismas opciones de movilidad.

Los peatones que surgen de $2 \mathrm{mh}$, siguen el mismo rumbo de $1 \mathrm{mh}$ solamente que en lugar de caminar por F-A-a-b, prefieren F-A-B, debido a que es más sencillo, sin embargo, esta acción genera un foco rojo, ya que no existen las condiciones de seguridad para dicho desplazamiento. Los transeúntes que provienen de 1,2,3 mh y se dirigen de $\mathrm{E}$ a D o de $\mathrm{E}$ a C y viceversa, provocan un segundo foco rojo debido a que prefieren usar las esquinas para cruzar la avenida. La razón lógica de este hecho es que posterior a que se implementara la ruta del Metrobús existían señalamientos para cruzar por dicho punto, inclusive aún quedan algunos de los DCT anteriores al cambio de infraestructura.

La puerta $4 \mathrm{mh}$ no tiene uso, los días en los que se realizó el estudio de campo nunca estuvo abierta. La entrada $5 \mathrm{mh}$, es la que presenta más flujo por estar localizada en un sitio estratégico en el que los peatones pueden acceder fácilmente al multicinema, la Alameda Central, Avenida Balderas, Avenida Juárez, Avenida Reforma, Centro Cultural Martí, Museo Diego Rivera, Museo Laboratorio Arte Alameda, comercios, Metrobús en sus tres direcciones, Juzgados del Tribunal Superior de Justicia del Distrito Federal, edificio de Relaciones Exteriores, entre otros. Desde este lugar (D) se trasladan hacia B, A o a por el camino corto, que es D-B creando los focos rojos antes señalados (imagen 5), ubicados del lado sur de la Avenida Paseo de la Reforma, a pesar de que la ruta segura para llegar a B, A o a es D-C-B. En el acceso $6 \mathrm{mh}$ encontramos las mismas características de afluencia y movilidad que en $5 \mathrm{mh}$, sólo que a diferencia de este último no ocasiona ningún punto de inseguridad debido a que su ubicación impide tomar riesgos, pues desemboca a trayectos con los DCT necesarios y suficientes.

Finalmente, está la salida $7 \mathrm{mh}$, a partir de ella se generan desplazamientos hacia la Avenida Paseo de la Reforma centro y la estación del transporte público instalada en b1. Aquí se generan dos trayectos, b1-C y b1-C-d. Estos recorridos no muestran ningún peligro para los peatones. La imagen 6, muestra de manera gráfica, la representación y funcionamiento del código vial del crucero descrito, dicho esquema permite observar lo complicado que es la movilidad en este sitio vial. 
Figura 6

Sintaxis I

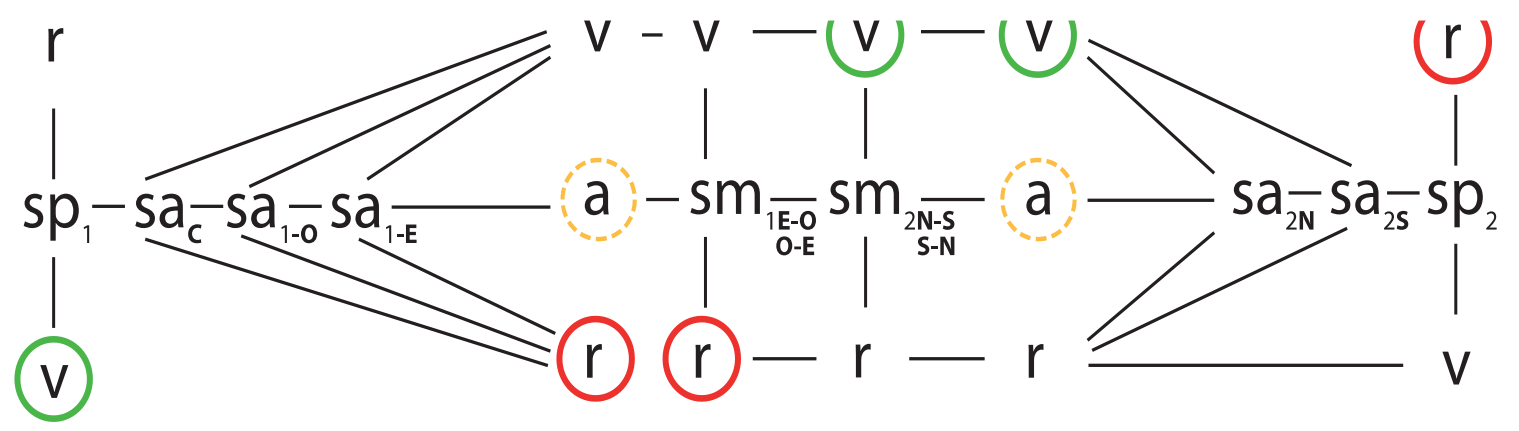

Sintaxis II

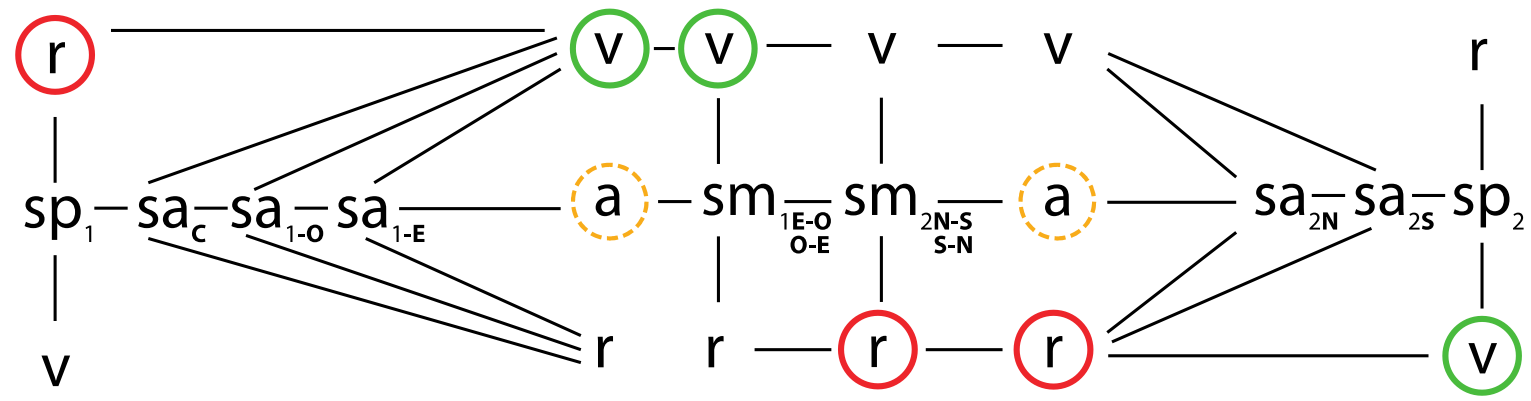

\begin{tabular}{|l|c|c|c|c|c|c|c|c|c|c|c|}
\hline & $\begin{array}{c}\text { semáforo } \\
\text { peatones }\end{array}$ & $\begin{array}{c}\text { semáforo } \\
\text { autos }\end{array}$ & $\begin{array}{c}\text { semáforo } \\
\text { Metrobús }\end{array}$ & $\begin{array}{c}\text { luz } \\
\text { verde }\end{array}$ & $\begin{array}{c}\text { luz } \\
\text { roja }\end{array}$ & $\begin{array}{c}\text { luz } \\
\text { ámbar }\end{array}$ & este & oeste & norte & sur & contraflujo \\
\hline Simbología & $\mathbf{s p}$ & $\mathbf{s a}$ & $\mathbf{s m}$ & $\mathbf{v}$ & $\mathbf{r}$ & $\mathbf{a}$ & $\mathbf{E}$ & $\mathbf{O}$ & $\mathbf{N}$ & $\mathbf{S}$ & $\mathbf{C}$ \\
\hline
\end{tabular}

Fuente: Santiago Osnaya, (2019)

A través del registro visual (levantamiento fotográfico, mapas, flujos peatonales, vehiculares, entre otros), se hizo una estimación de la frecuencia con que las personas transitan por cada uno de los trayectos. Fue así, que se pudieron determinar los espacios que presentan mayor movilidad e inseguridad (ver figura 5). En el rango temporal de la observación (6:00 am a $21.00 \mathrm{pm})$ todos los lugares temporales de este caso de estudio mostraron gran movimiento. A continuación, se realiza una interpretación de cada trayectorias, para determinar las posibles causas de riesgo vial en términos de la aplicación y función del código vial.

\section{CONTEXTO VIAL Y SU ESPECIFICIDAD COMUNICATIVA PARA GENERAR EL} HÁBITO (CRUCE DE VIALIDADES) CON BASE A LA FUNCIÓN Y APLICACIÓN DEL CÓDIGO VIAL.

A partir de las técnicas de investigación se ubicaron los elementos que permiten el suceso de traslado entre una y otra acera. Los espacios públicos analizados desde un campo en contextualización o de significación dieron la pauta para entender las interrelaciones y las posibles causas que ocasionan los puntos de peligro para los transeúntes. Esta referencia ayudó a plantear el sitio donde se realizarían las 
entrevistas con los usuarios y comprender mejor la correspondencia entre el mensaje del signo (DCT) y su interpretación.

La figura 7, muestra como fue categorizado cada uno de los trayectos viales, con base en la simbología propuesta (cuadro IV). En estos campos de interacción se proyectan las reglas, las normas y convenciones de la ideología y la cultura determinada, reflejando el significado que cada uno de los actores sociales le asigna a los DCT en términos de su seguridad. Dependiendo de esto será el grado de cumplimiento en torno a la normatividad del código y el reglamento de tránsito. En este sentido fue posible observar que ambos funcionan como esquemas flexibles, es decir, si bien pueden adaptarse y ajustarse a las necesidades de cada individuo, dicha flexibilidad también promueve escenarios de conflicto. Más adelante en el apartado "explicación de las trayectorias" se abundará en cada uno de los casos a través de la interpretación semiótica de los mismos.

\begin{tabular}{|l|l|}
\hline \multicolumn{2}{|c|}{ Cuadro IV } \\
\hline \multicolumn{1}{|c|}{ Simbología } & \multicolumn{1}{c|}{ Descripción } \\
\hline & $\begin{array}{l}\text { Este símbolo denota el funcionamiento correcto del código } \\
\text { vial derivado de una idónea sintaxis. }\end{array}$ \\
\hline & $\begin{array}{l}\text { Este símbolo denota una disfunción del código vial derivado } \\
\text { de la ausencia de una o más señales. }\end{array}$ \\
\hline & $\begin{array}{l}\text { Este símbolo denota una disfunción del código vial, ya que, } \\
\text { aunque existe el señalamiento, éste no está acoplado } \\
\text { sintagmáticamente al conjunto de signos. }\end{array}$ \\
\hline & $\begin{array}{l}\text { Este símbolo denota ruido (natural o artificial) en el } \\
\text { intérprete, lo que impide que semánticamente la función del } \\
\text { código sea correctamente interpretada, generando duda en } \\
\text { el usuario. }\end{array}$ \\
\hline
\end{tabular}

Fuente: Santiago Osnaya (2020) 


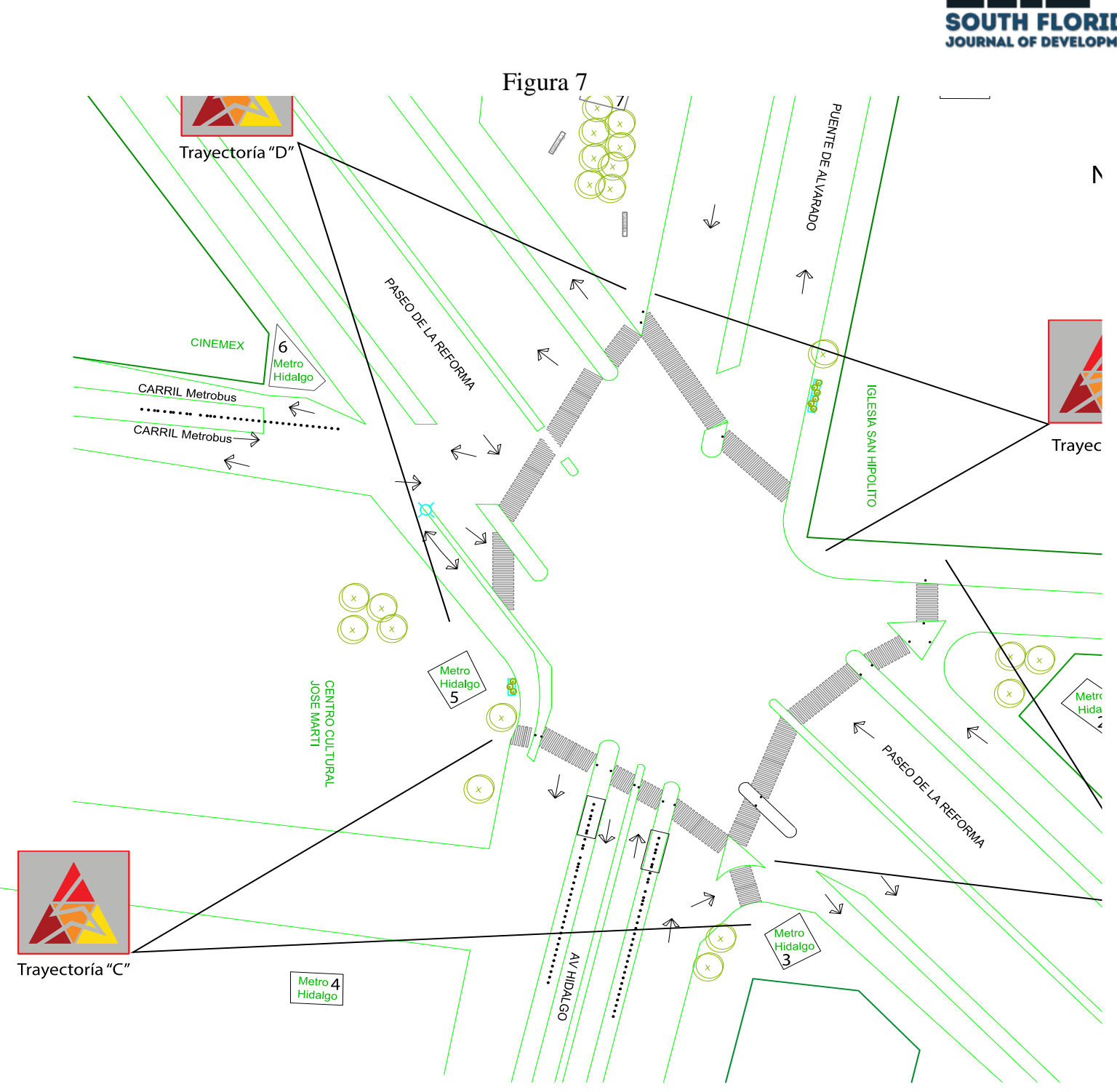

Fuente: Santiago Osnaya, 14/12/2015

\section{EXPLICACIÓN DE TRAYECTORIAS}

Trayectoria "A"

Para el estudio de las trayectorias que corresponden a este crucero se utilizará como referencia la figura 5. Esta senda presenta uno de los cinco focos rojos de la intersección debido a que los usuarios utilizan las aristas de las aceras para atravesar la avenida Puente de Alvarado en su lado oeste (A-B), en lugar de optar por el paso designado para tal fin, trayectoria a-b. Se observó que algunos peatones aún tienen el hábito de cruzar por las esquinas de este trayecto, ya que, antes de la creación del Metrobús (línea 4 y 3) este era el lugar marcado para tal fin. La inspección de campo demuestra que no se llevó a cabo un reajuste de los DCT, ya que aún se observan señalamientos que denotan los anteriores cruces, lo que ocasiona ruido visual y confusión en los usuarios. Esto genera que los transeúntes sigan utilizando la vieja ruta, pues no han sido removidos los antiguos dispositivos. Cuando la infraestructura de calle 
Figura 8
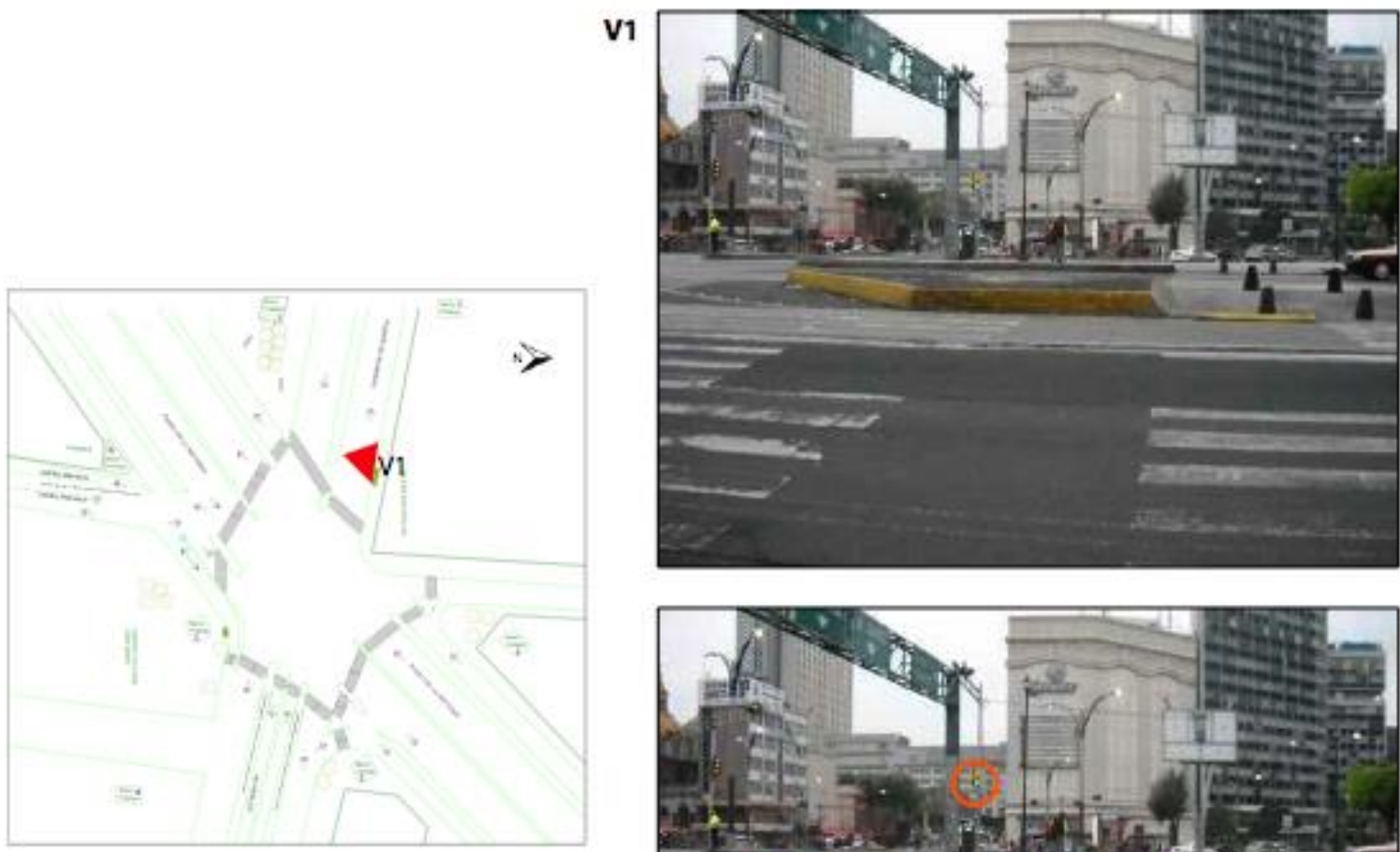

El color naranja indica los DCT que no fueron retirados o modificados

El color verde señala el nuevo trayecto peatonal

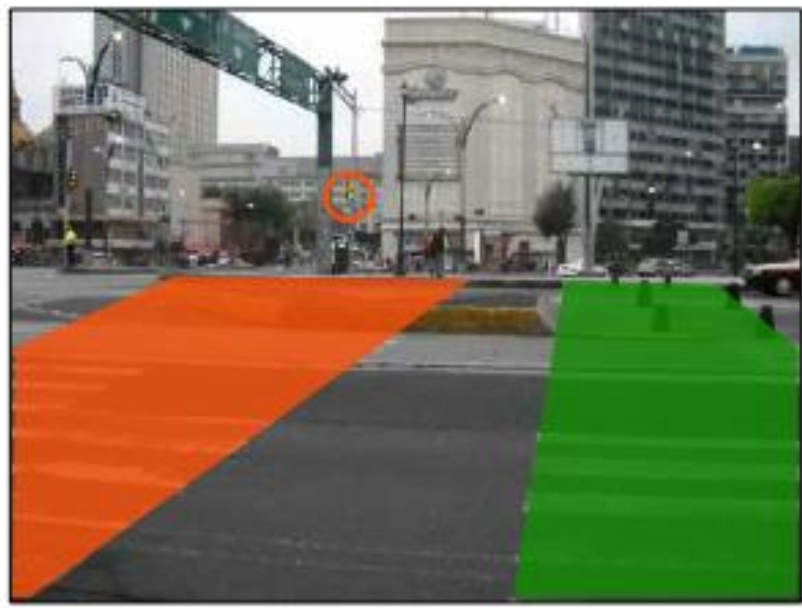

Imagen 57. Vista 1

La imagen muestra la falta de adecuación de los DCT, a partir de la creación del metrobús

Fuente: Santiago Osnaya, 22 de Diciembre 2012, 07:30 am

La figura 9, muestra a los usuarios haciendo uso del trayecto incorrecto e inseguro debido a que aún existen las franjas y los semáforos peatonales (marcados con color rojo) antiguos. Además, una vez que los peatones llegan a la banqueta que se encuentra del lado de la iglesia de San Hipólito (lado norte del crucero), estos tienen que caminar por el arroyo vehicular debido a que el acceso de la acera se encuentra bloqueado; ello producto de las adecuaciones que trajo consigo la construcción del Metrobús (ver figura 10). 
Figura 9

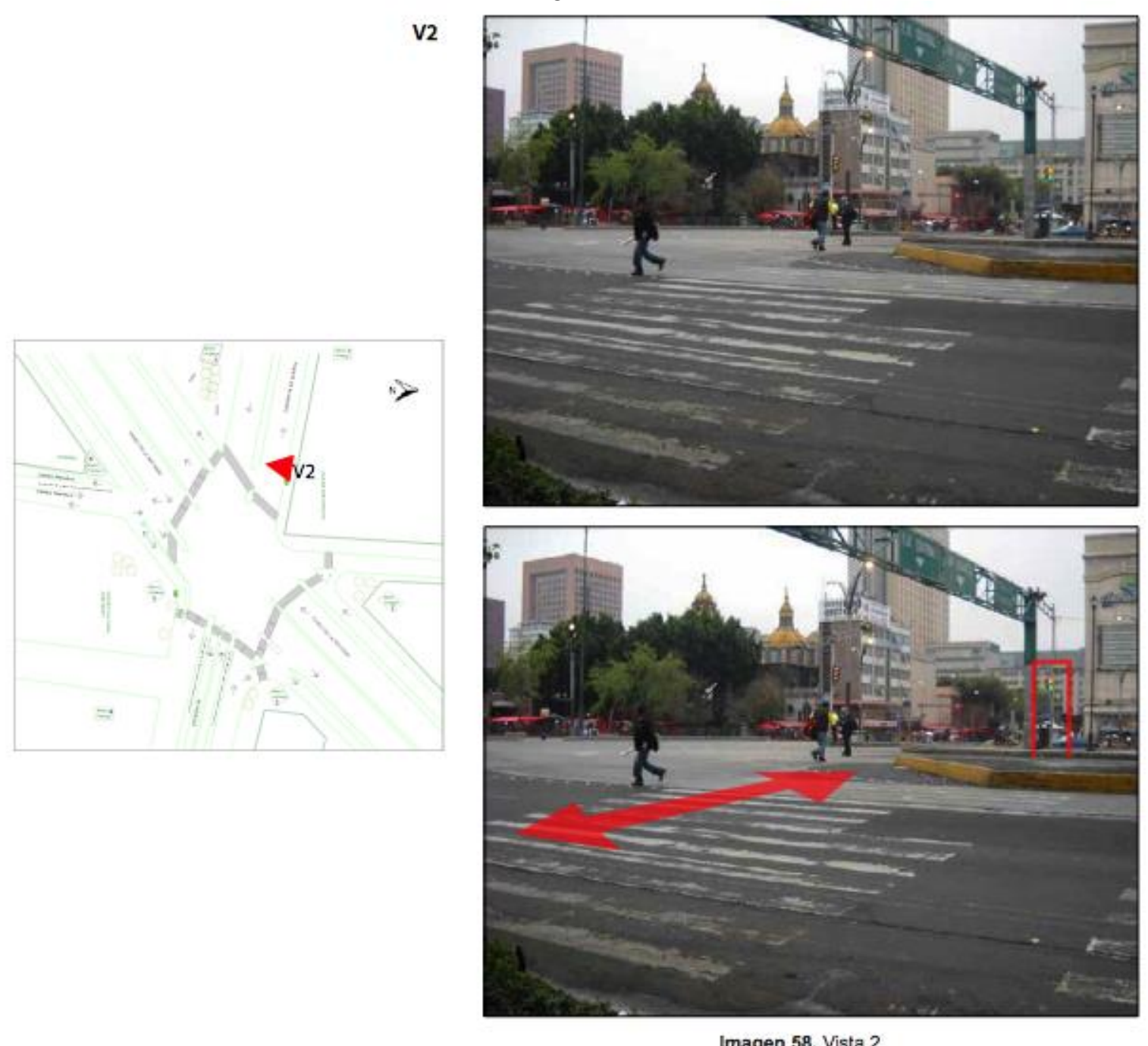

Imagen 58. Vista 2

Cruce de peatones por un trayecto inseguro

Fuente: Santiago Osnaya, 22 de Noviembre 2012, 07:00 pm 


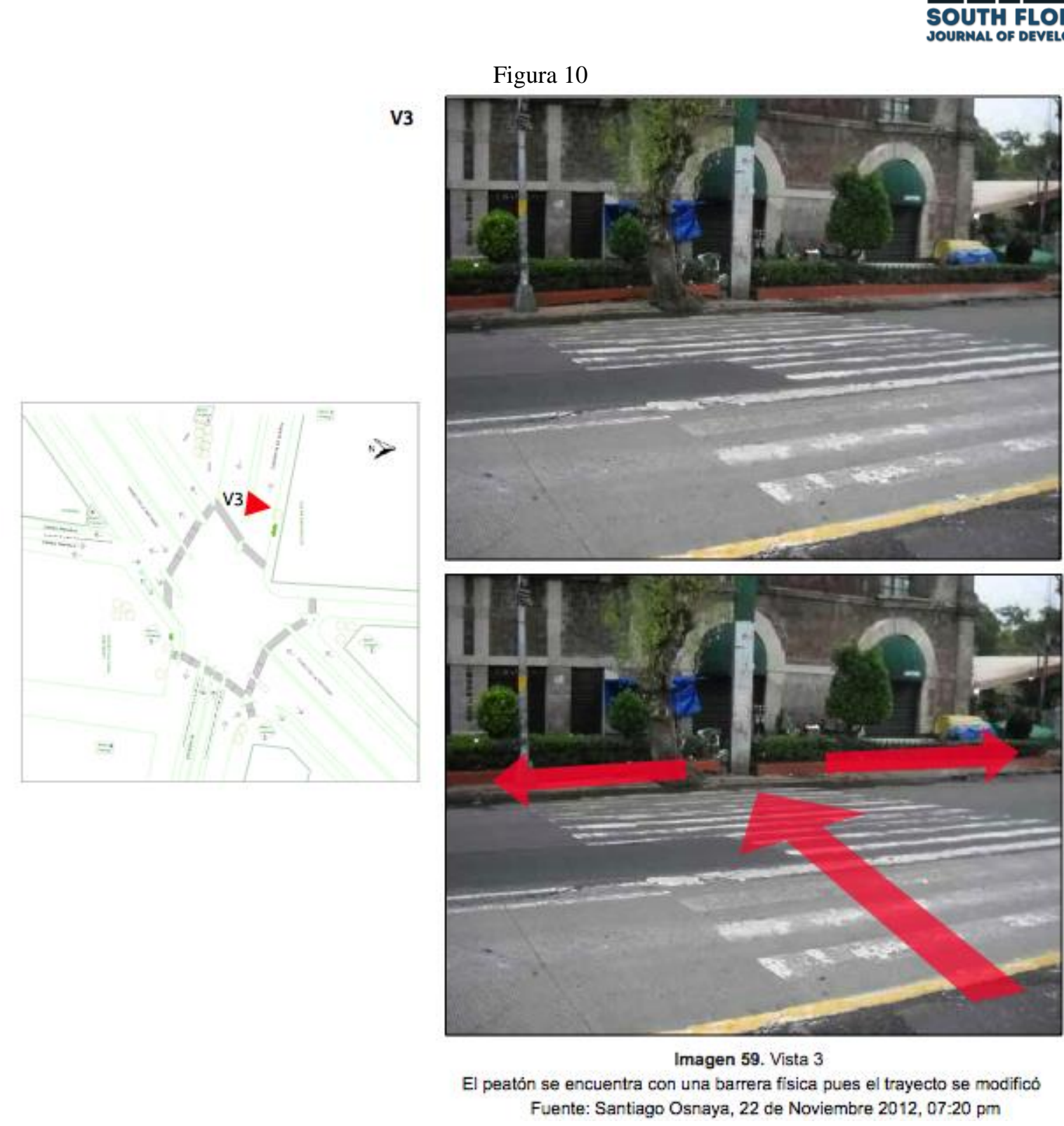

Otra de las situaciones que hace del trayecto A-B un cruce inseguro, es una isla mediana de refugio vial que no cuenta con las características mínimas de seguridad peatonal. Sin embargo, los transeúntes la utilizan para cruzar la avenida, aún y cuando carece de DCT (figura 11). Esta situación implica que las personas tengan que permanecer de cinco a 10 minutos parados en ese lugar para poder pasar la avenida. Los más audaces esquivan los automóviles o se atraviesan corriendo para evitar sufrir algún tipo de percance (ver figuras 12,13 y 14 ). 


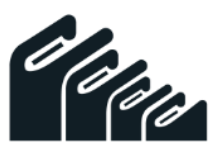

SOUTH FLORIDA

JOURNAL OF DEVELOPMENT

Figura 11

V4
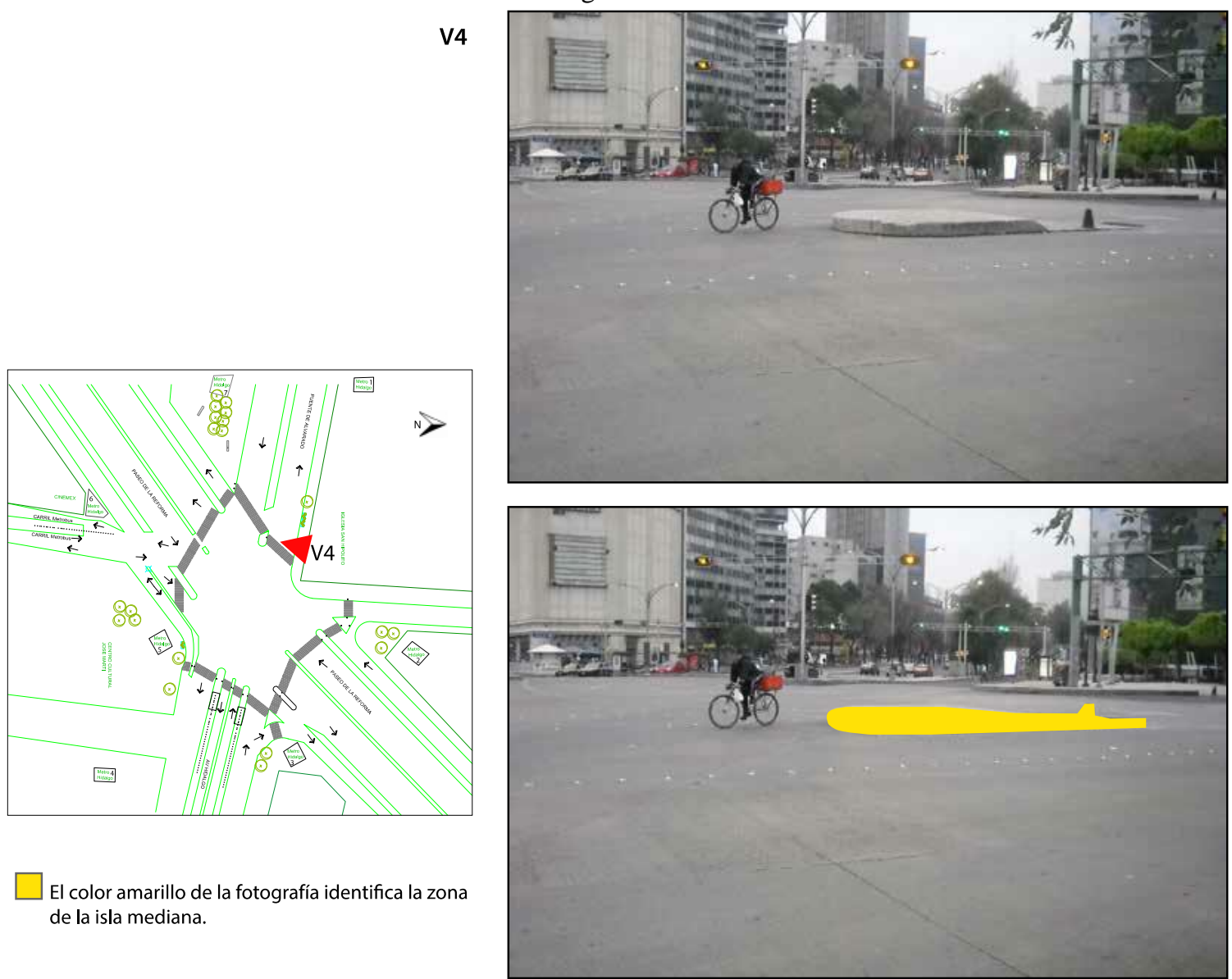

Imagen 60. Vista 4

Isla mediana sin dispositivos que garanticen la seguridad del peatón Fuente: Santiago Osnaya, 22 de Noviembre 2012, 07:10 am

Figura 12

V5
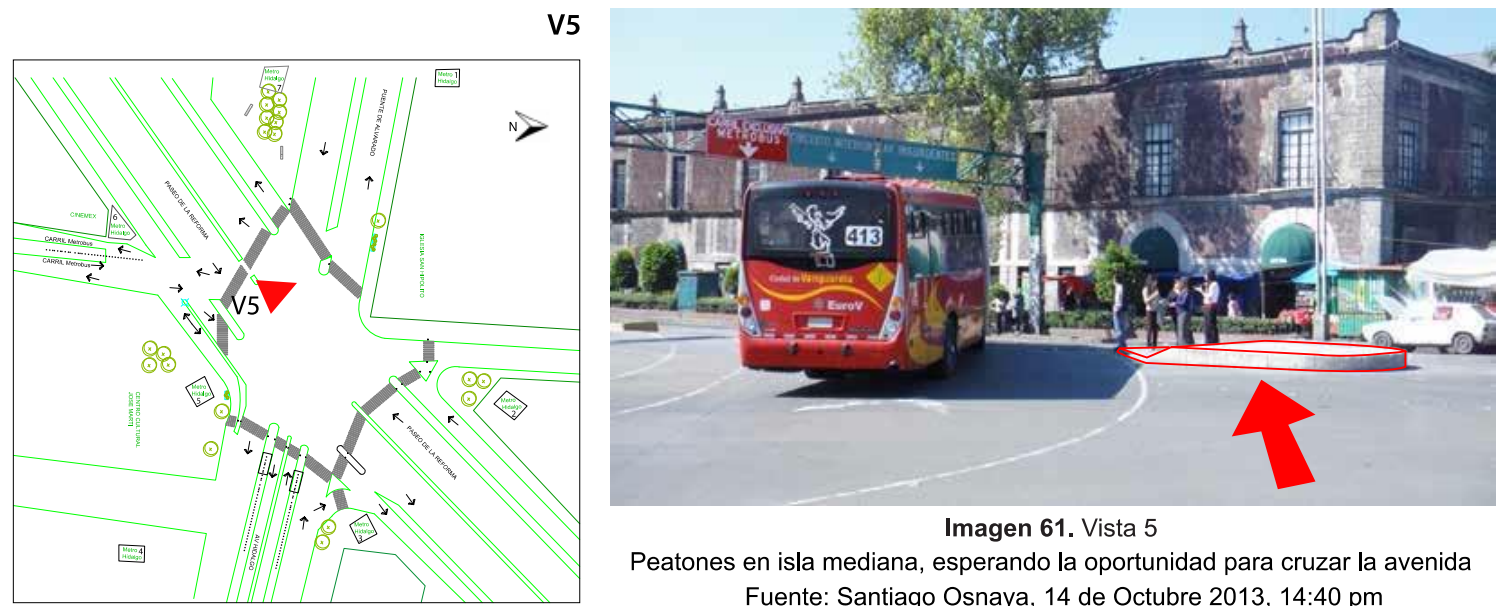

Imagen 61. Vista 5

Peatones en isla mediana, esperando la oportunidad para cruzar la avenida Fuente: Santiago Osnaya, 14 de Octubre 2013, 14:40 pm 


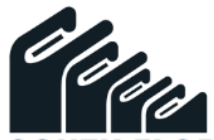

SOUTH FLORIDA

JOURNAL OF DEVELOPMENT

Figura 13

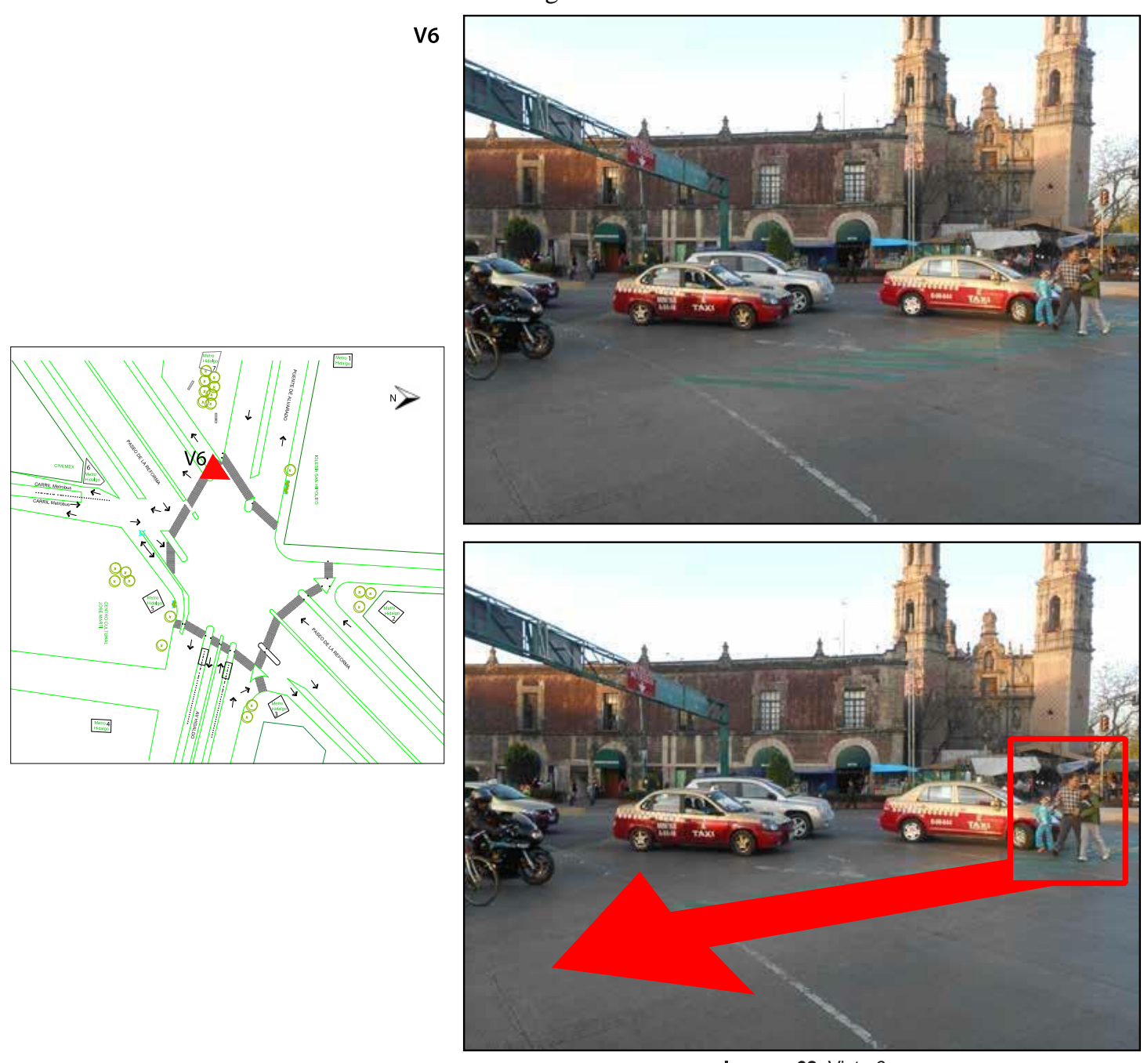

Imagen 62. Vista 6

Peatones arriesgando su vida en pleno flujo vehicular para cruzar la avenida Fuente: Santiago Osnaya, 22 de Noviembre 2012, 07:20 pm

Figura 14

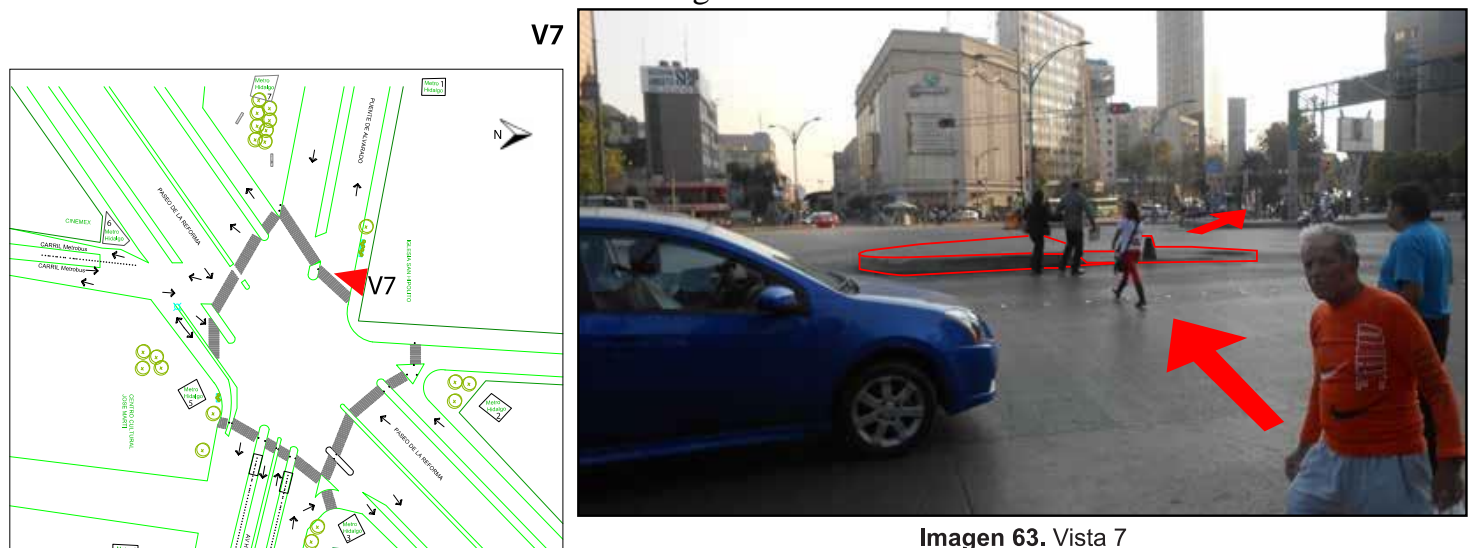

Peatones utilizando isla mediana como apoyo para atravesar la avenida Fuente: Santiago Osnaya, 30 de Enero 2014, 17:00 pm

El cuadro $\mathrm{V}$, exhibe la evaluación del trayecto a-b utilizando la herramienta de análisis, función del código vial (Osnaya, 2019). Si bien, las técnicas de investigación permitieron tipificar este cruce con 
Cuadro V

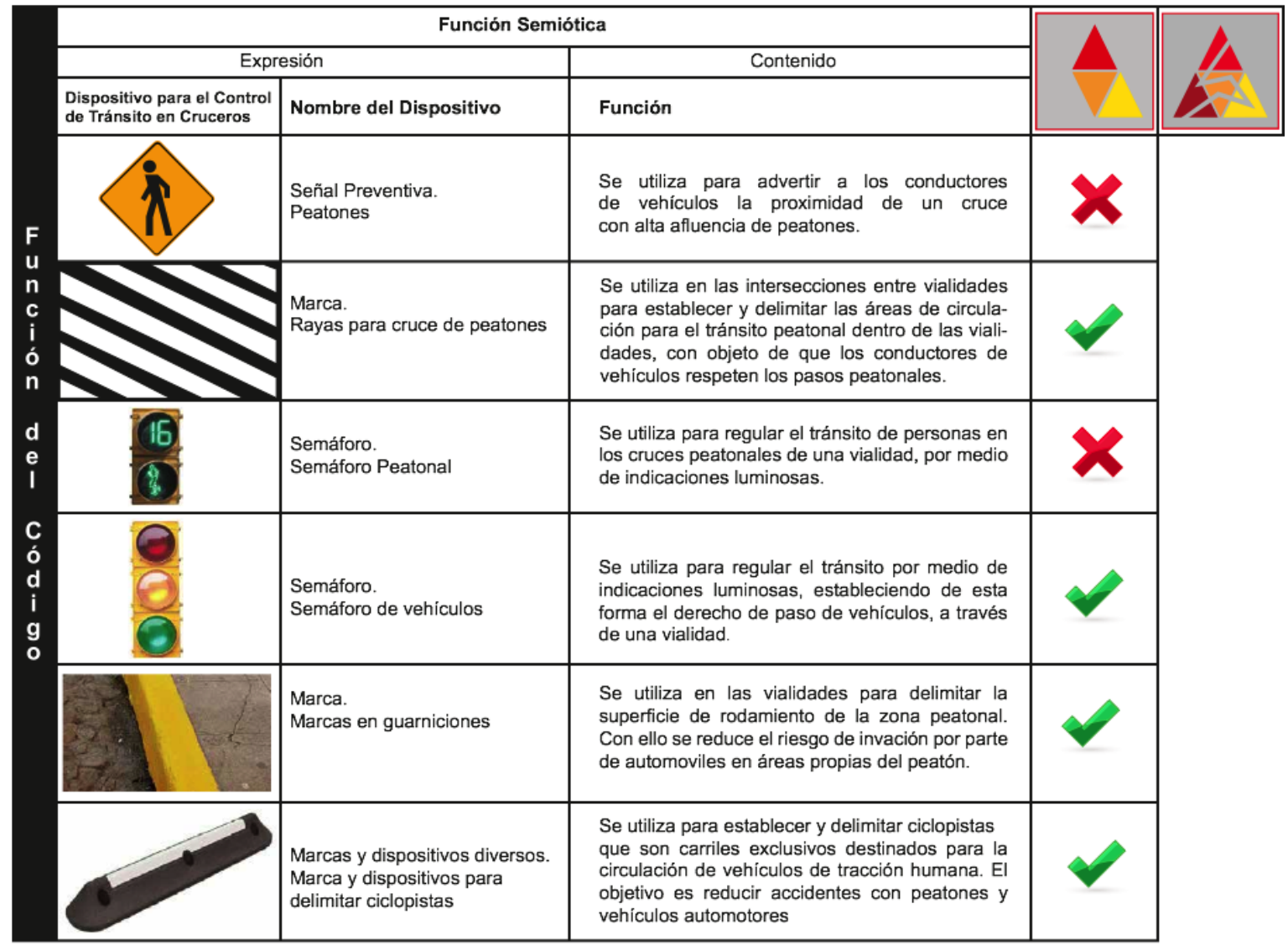

Fuente: Santiago Osnaya, 06/07/2017

\section{Trayectoria "B"}

El recorrido F-E (figuras 15 y 16) no presenta mayores complicaciones para los peatones, sin embargo, al ser un cruce muy largo, el tiempo de los semáforos resulta muy corto para las personas de la tercera edad, discapacitados, mujeres embarazadas, entre otros. De ahí que este tipo de usuarios tengan que cruzar la avenida en el tiempo de dos semáforos rojos. 
Figura 15

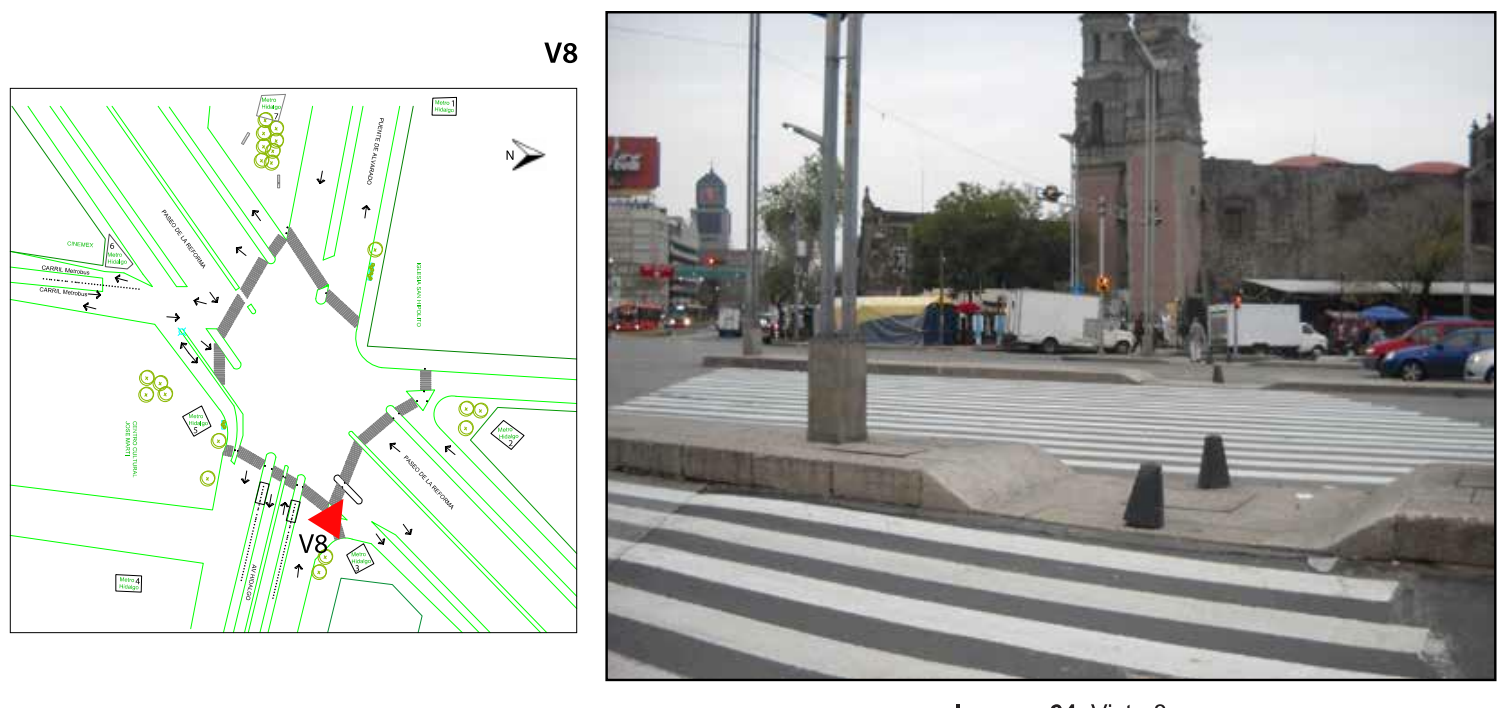

Imagen 64. Vista 8

Cruce F-E sobre Avenida Paseo de la Reforma

Fuente: Santiago Osnaya, 22 de Noviembre 2012, 07:35 am

Figura 16

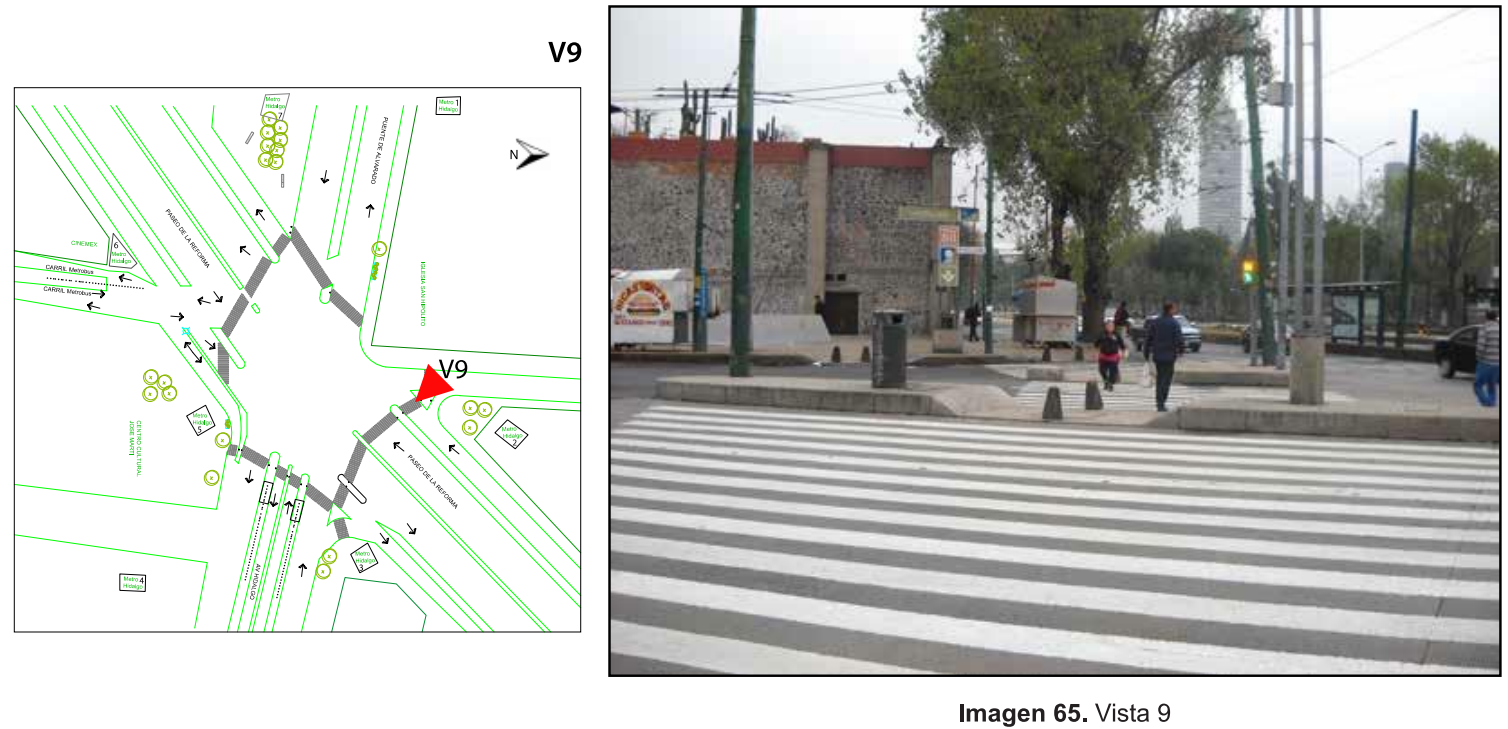

Cruce E-F sobre Avenida Paseo de la Reforma

Fuente: Santiago Osnaya, 22 de Noviembre 2012, 07:30 am

El análisis del cuadro VI, muestra que el cruce cuenta con casi todos los DCT aplicados en el lugar, además de encontrarse en buen estado físico, es decir, la aplicación de la pintura es reciente, todos los semáforos peatonales y vehiculares funcionan. El único inconveniente es que no cuenta con suficientes dispositivos del tipo señal preventiva de peatones, pues aún y cuando los conductores tienen buena visibilidad, siempre es necesario dicho señalamiento para advertir a los automotores sobre el cruce de peatones para que extremen sus precauciones. 
Cuadro VI

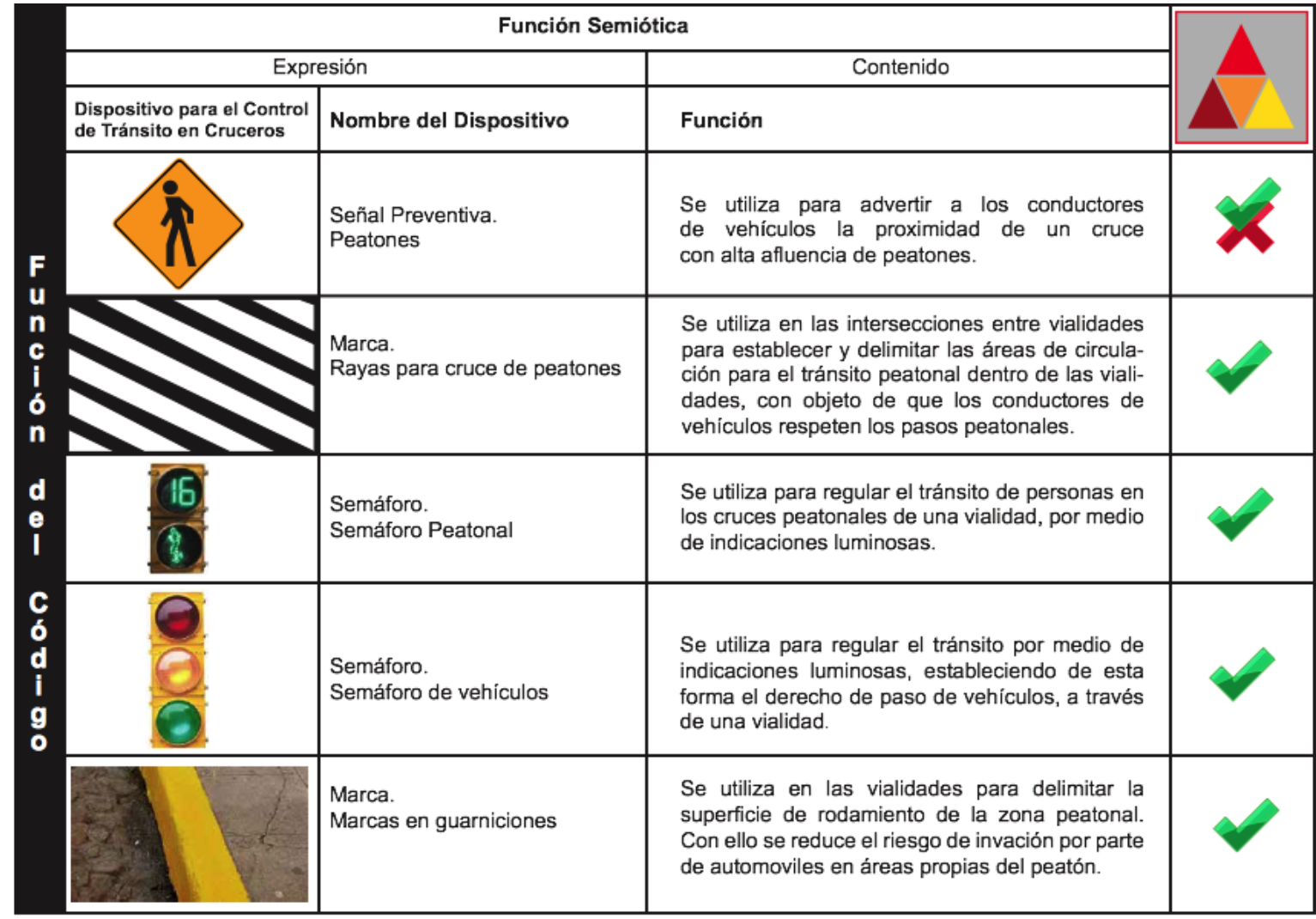

Fuente: Santiago Osnaya, 06/08/2017

Trayectoria "C"

En términos de disfunción del código vial y la conducta de los usuarios, esta ruta es similar al trayecto "A", ya que se presentan dos posibilidades para que las personas pasen de un lado al otro de la avenida. Como mejor opción está el camino nuevo, el cual fue implementado a partir de que fueron creadas las líneas del Metrobús (3-4). La segunda ruta, es la antigua, esta permanece porque no fueron eliminados los DCT anteriores; los elementos viales que aún permanecen son los semáforos y las rayas peatonales. Esta situación favorece que algunos usuarios sigan haciendo uso de este trayecto, a pesar de poner en peligro su integridad personal (ver figuras 17, 18 y 19). 


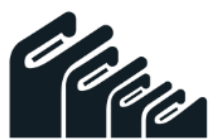

SOUTH FLORIDA

JOURNAL OF DEVELOPMENT

Figura 17

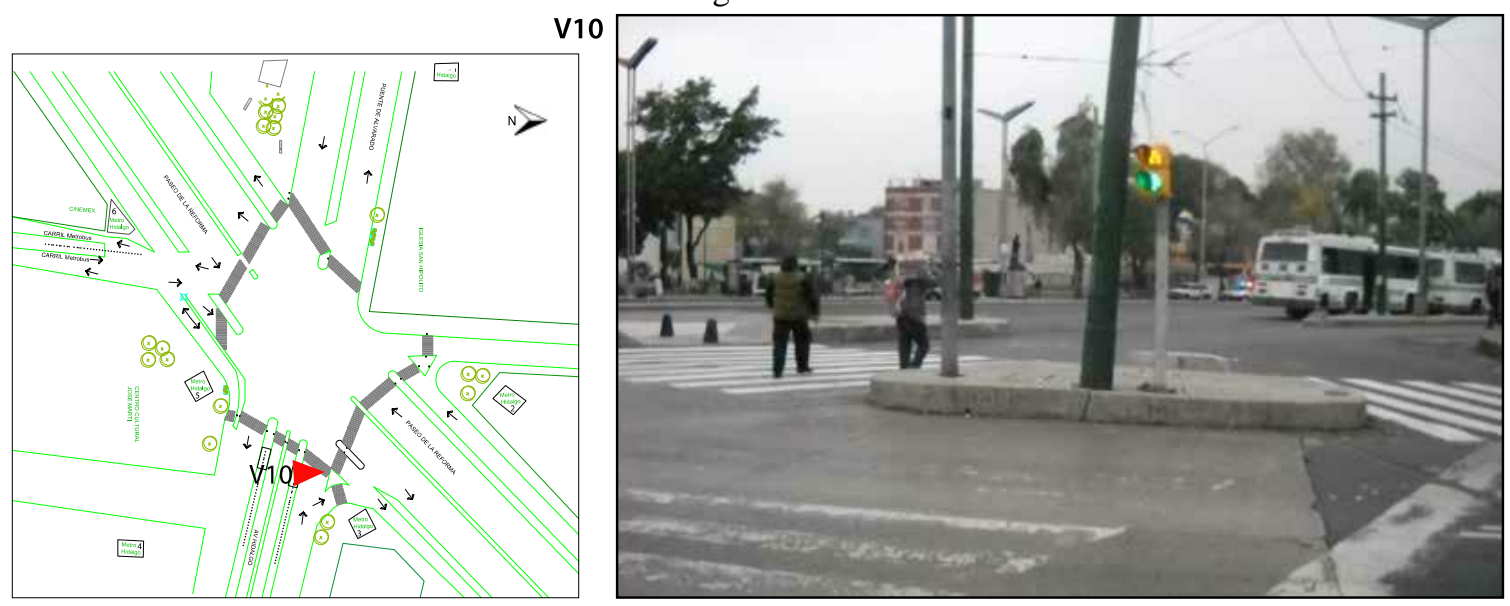

Imagen 66. Vista 10

Semáforo de antiguo trayecto peatonal

Fuente: Santiago Osnaya, 22 de Noviembre 2012, 7:20 pm

Figura 18
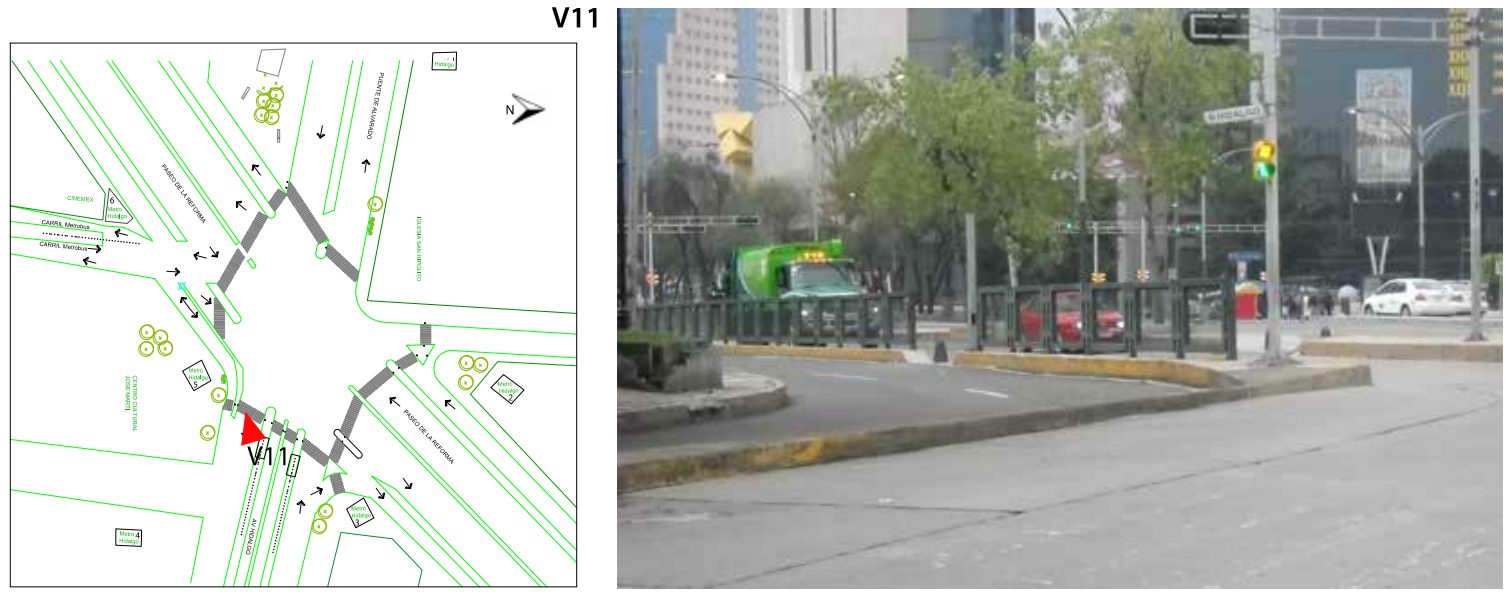

Imagen 67. Vista 11

Semáforo de antiguo trayecto peatonal

Fuente: Santiago Osnaya, 22 de Noviembre 2012, 7:20 pm

Figura 19
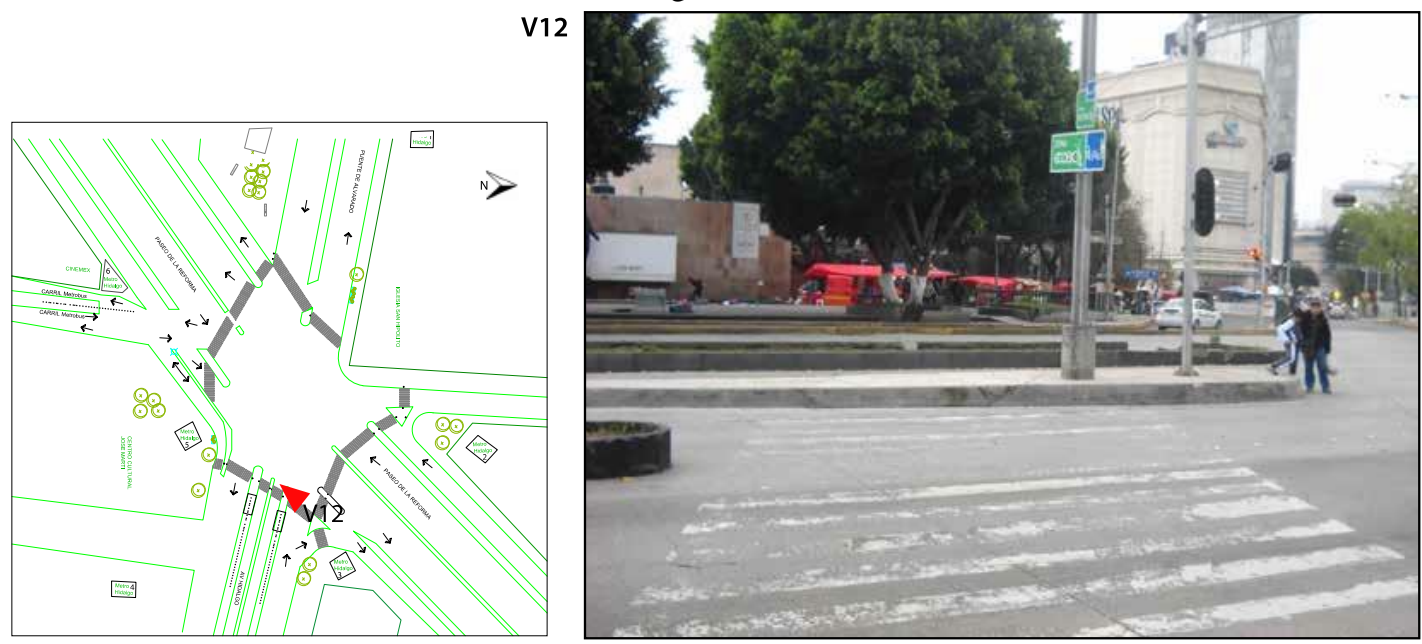

Imagen 68. Vista 12

Franjas peatonales de antiguo trayecto peatona

Fuente: Santiago Osnaya, 22 de Noviembre 2012, 7:36 am 
En las figuras 20 y 21 se muestra que todavía permanecen los semáforos de la anterior trayectoria peatonal, la figura 19 muestra aún marcadas las cebras (cruce de peatones). Estas situaciones generan que los transeúntes utilicen esta ruta que carece de condiciones seguras.

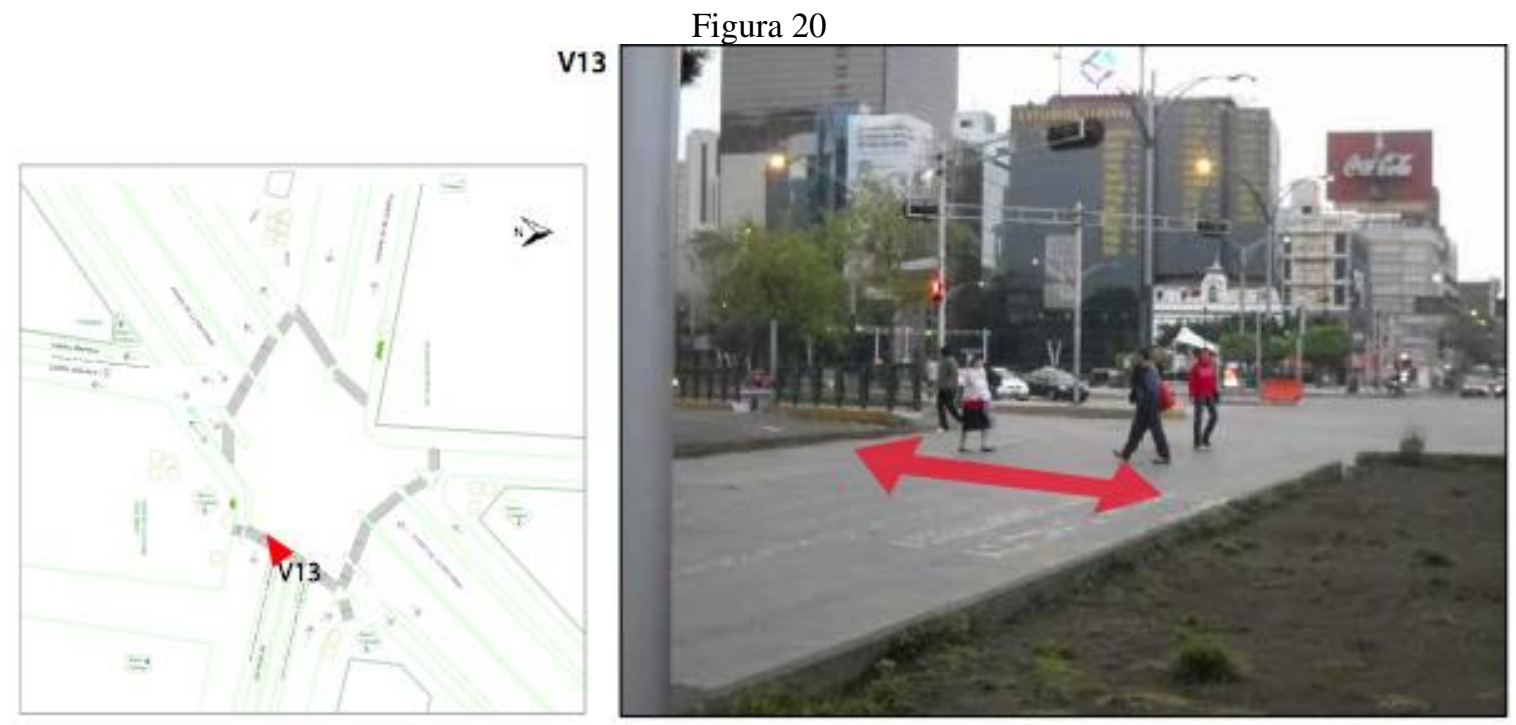

Imagen 69. Vista 13

Peatones haciendo uso de antiguo trayecto peatonal Fuente: Santiago Osnaya, 22 de Noviembre 2012, 07:21 am

Figura 21

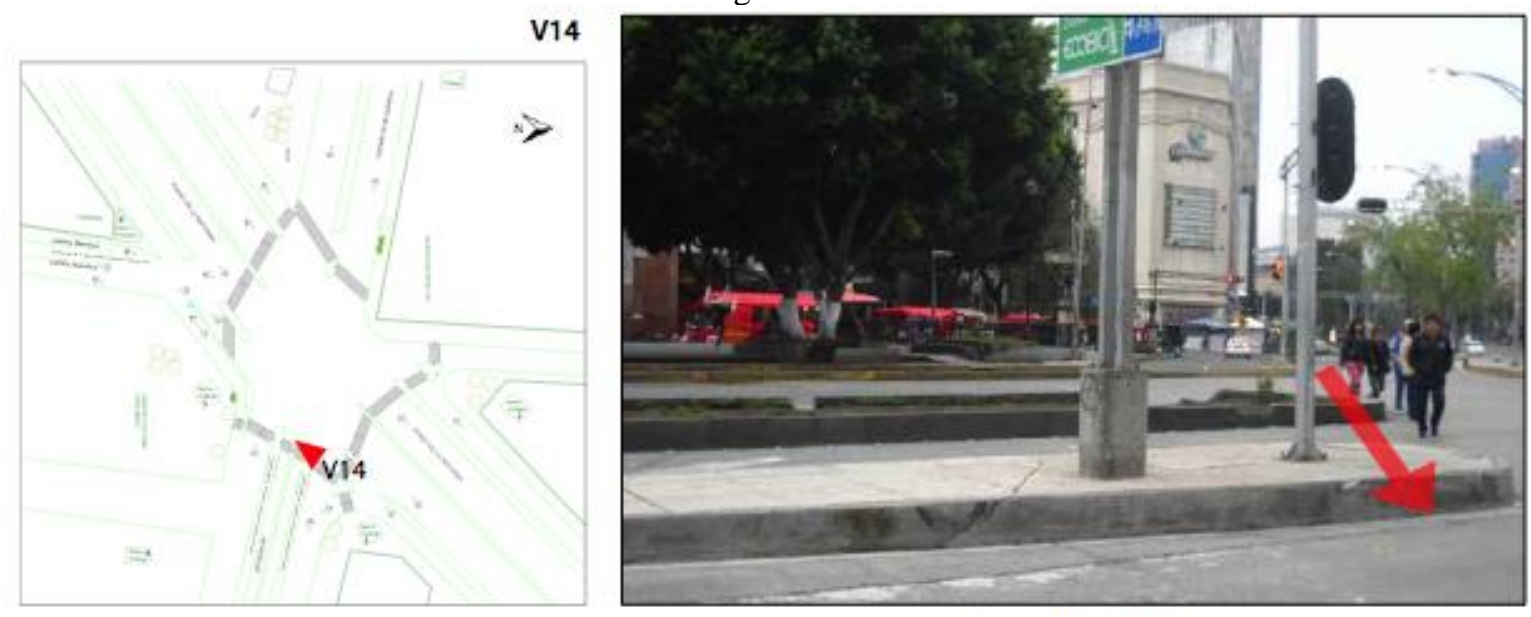

Imagen 70. Vista 14

Peatones haciendo uso de antiguo trayecto peatona:

Fuente: Santiago Osnaya, 22 de Noviembre 2012, 07:23 am

Otra circunstancia desfavorable para los transeúntes en este trayecto es la falta de marcas sobre guarniciones (ver figura 23). La distinción de los límites entre la trayectoria peatonal y vehicular es de vital importancia dado que ello alerta a los automotores a no invadir las sendas de las personas a pie y que suceda un accidente. La figura 22, muestra claramente las afectaciones que ha sufrido la guarnición, se presupone que al no existir las marcas correspondientes (de color amarillo) es fácil que el conductor 
produzca daños a la infraestructura vial, ya que con poca luz es difícil diferenciar la zona designada para el peatón.

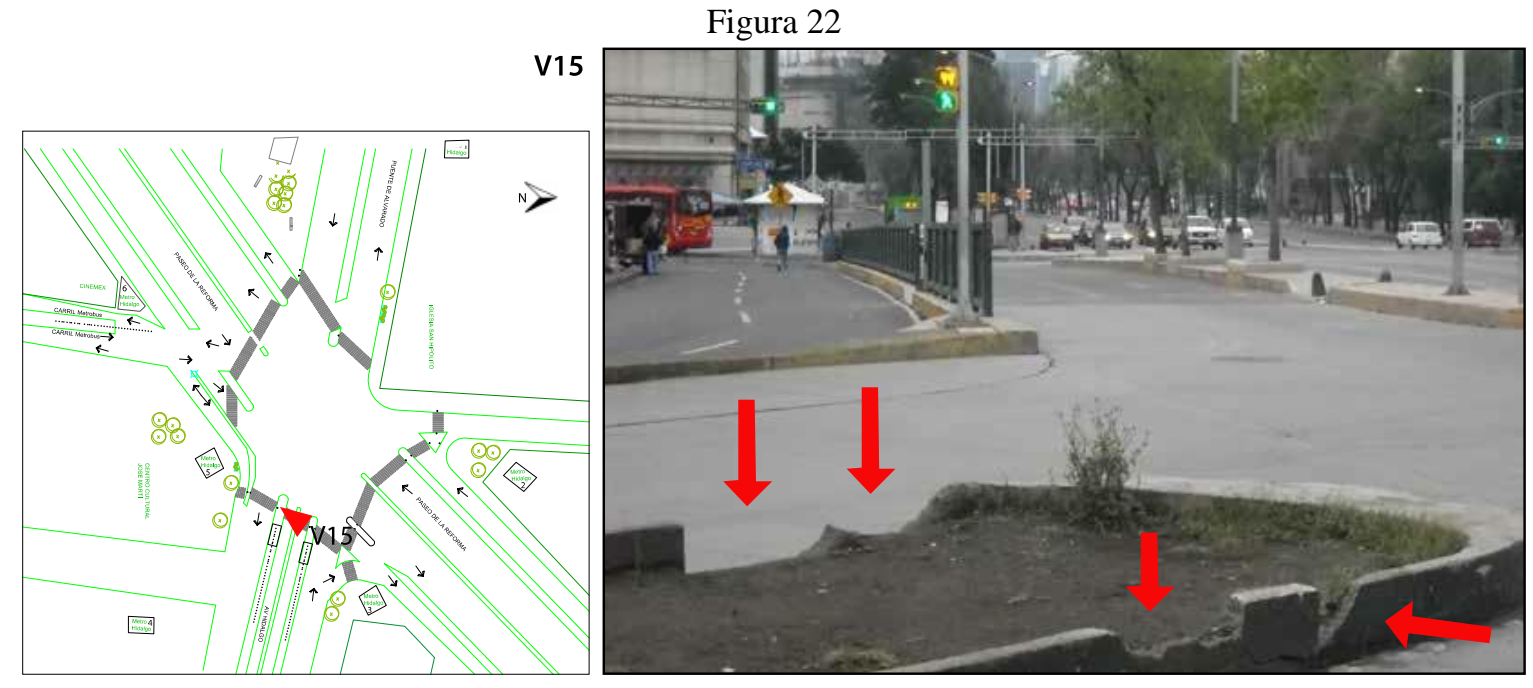

Imagen 71. Vista 15

Los automotores han provocado daños en la guarnición Fuente: Santiago Osnaya, 22 de Noviembre 2012, 07:40 am

Figura 23

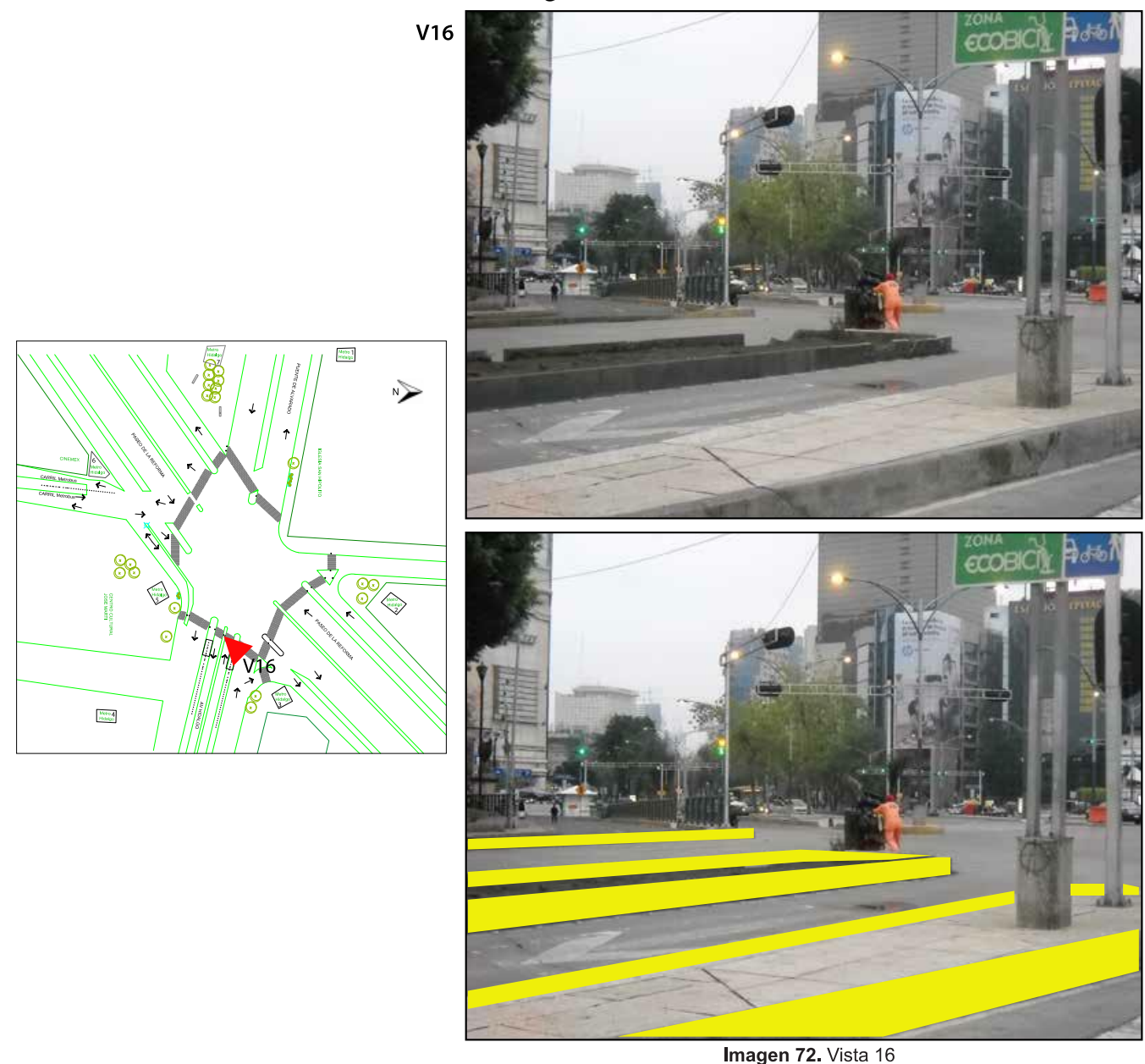

Ausencia de marcas en guarniciones

Fuente: Santiago Osnaya, 22 de Noviembre 2012, 07:22 pm 
Figura 24
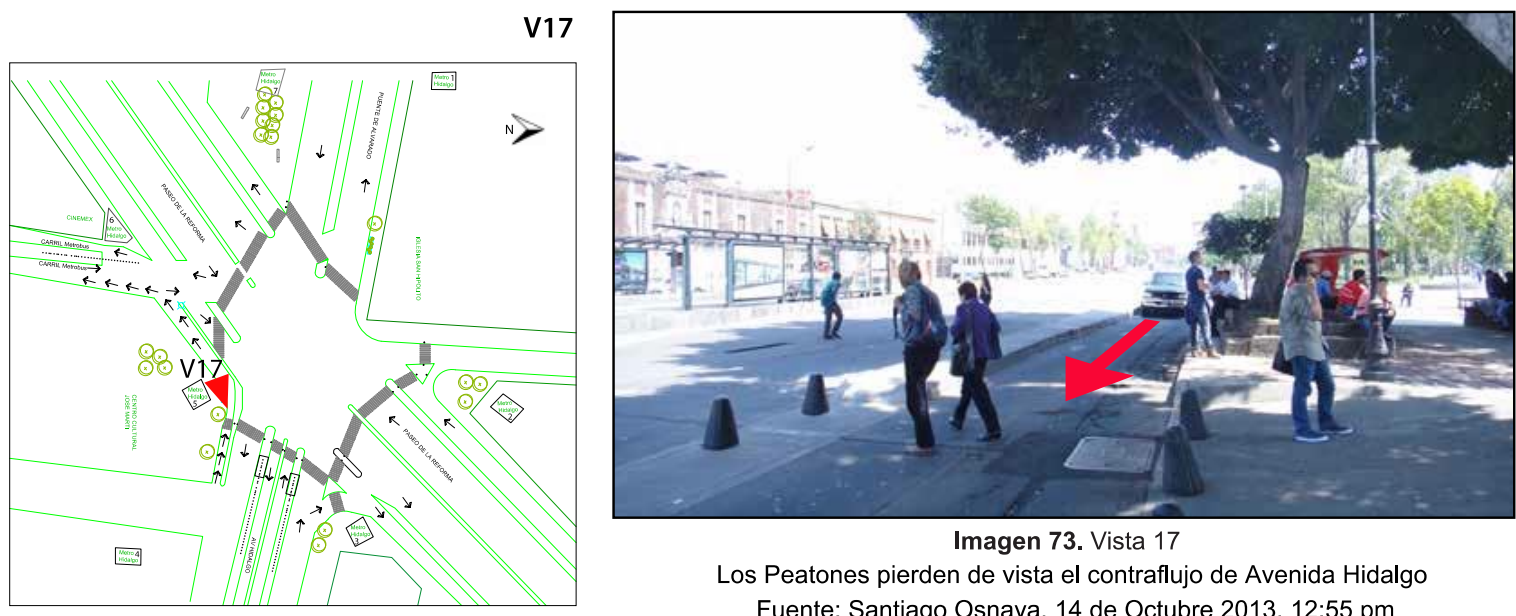

Imagen 73. Vista 17

Los Peatones pierden de vista el contraflujo de Avenida Hidalgo Fuente: Santiago Osnaya, 14 de Octubre 2013, 12:55 pm

Figura 25
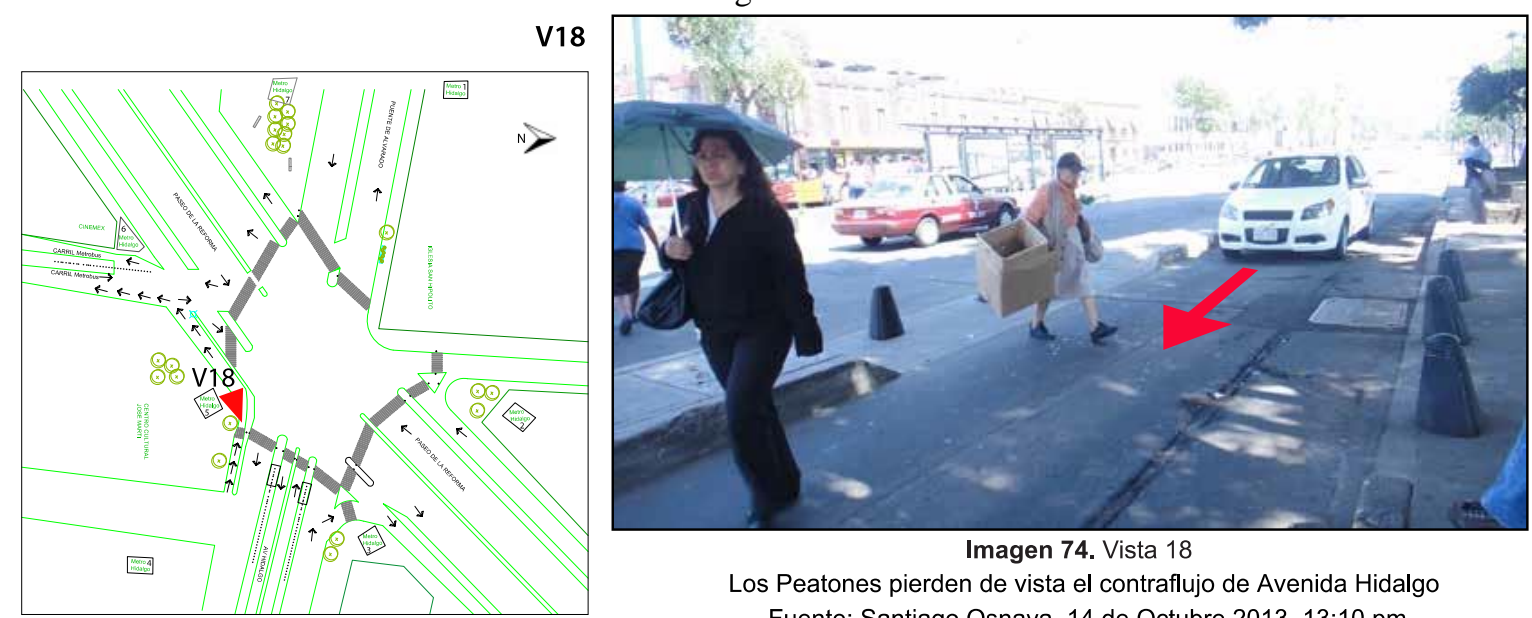

Imagen 74. Vista 18

Los Peatones pierden de vista el contraflujo de Avenida Hidalgo Fuente: Santiago Osnaya, 14 de Octubre 2013, 13:10 pm 
Figura 26
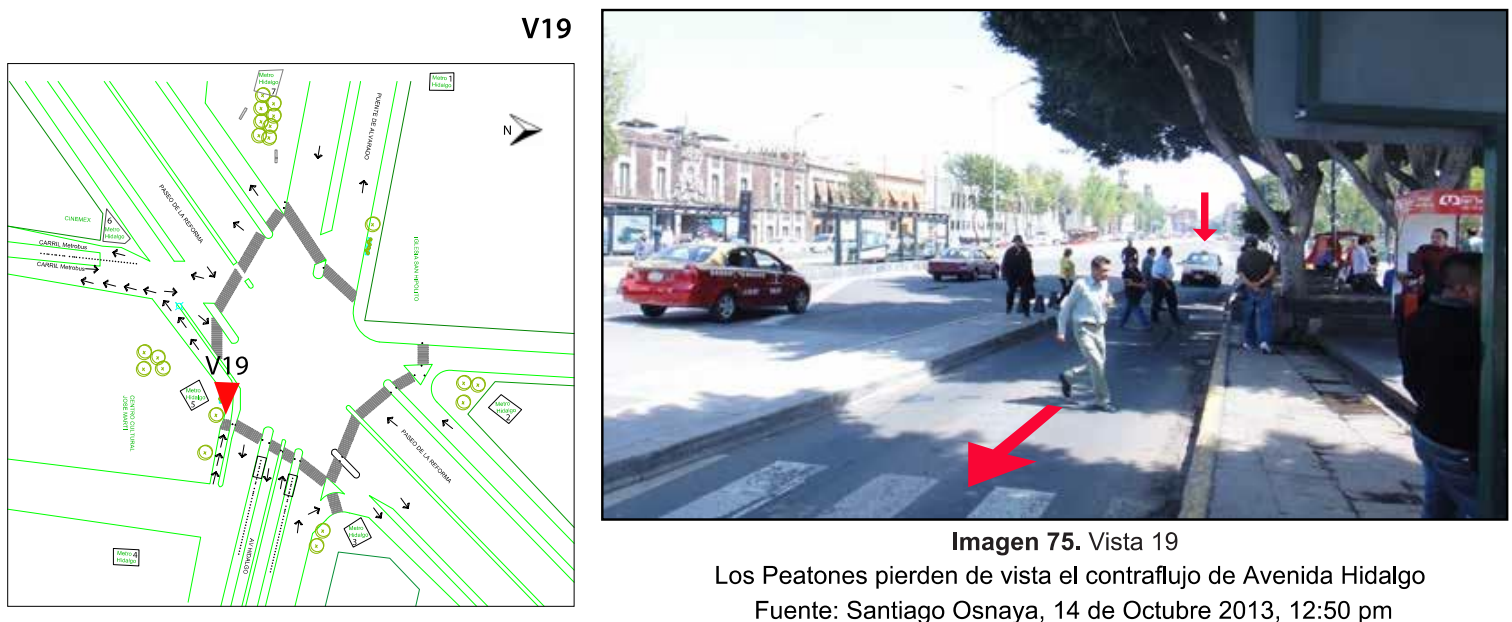

Imagen 75. Vista 19

Los Peatones pierden de vista el contraflujo de Avenida Hidalgo Fuente: Santiago Osnaya, 14 de Octubre 2013, 12:50 pm

En el cuadro VII, se muestra la evaluación de la trayectoria en relación con la función y aplicación del código vial. Se destaca que además de que existe la ausencia de dispositivos, se crea un ruido en los usuarios debido a un segundo trayecto que no debería existir. Esta problemática da origen a una situación paradójica, ya que, el trayecto que debería estar en desuso cuenta con semáforos peatonales y el paso actual no los tiene.

Cuadro VII

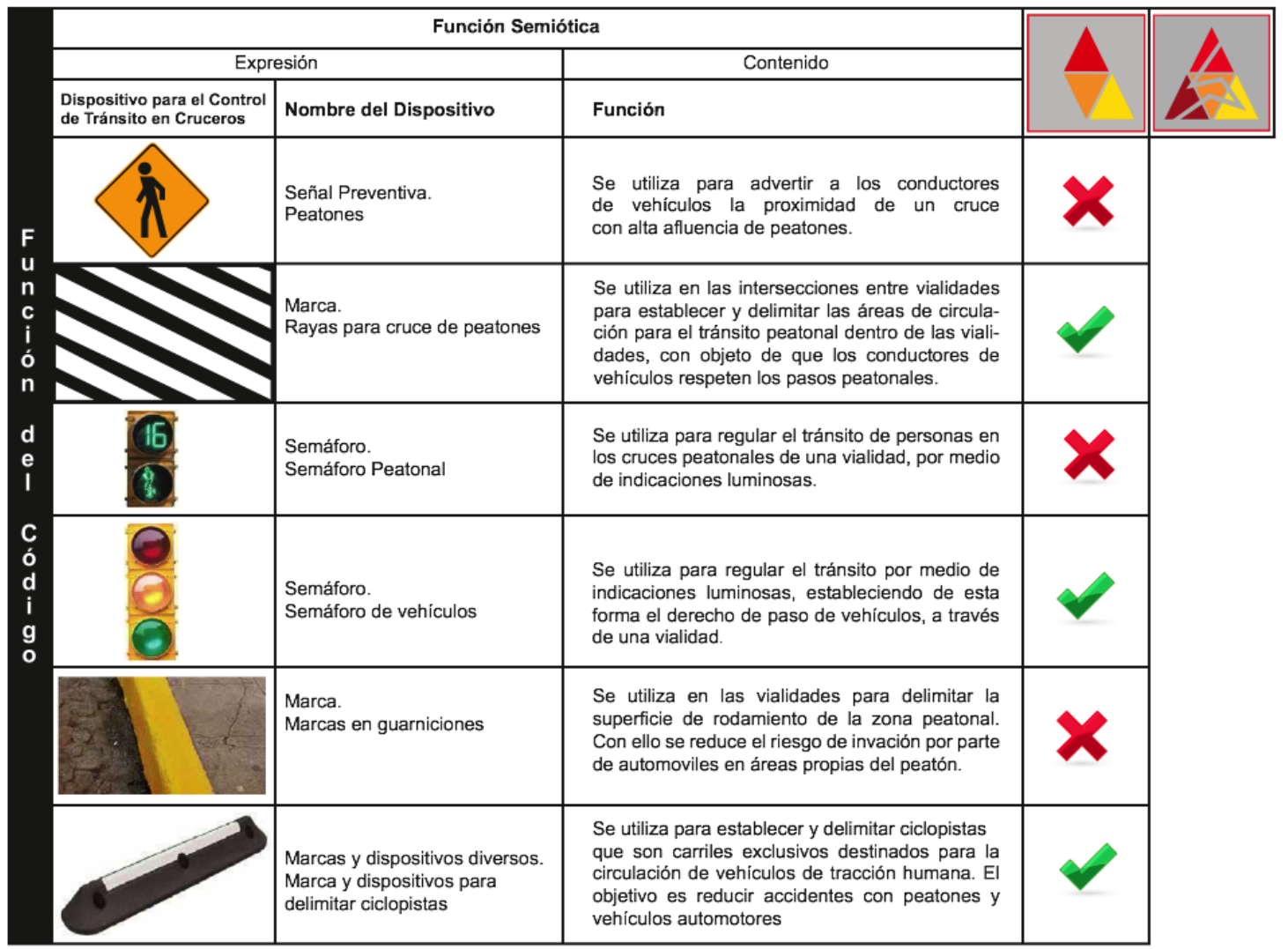

Fuente: Santiago Osnaya, 08/09/2017 
Trayectoria "D"

Esta ruta presenta un trayecto seguro (figuras 27, 28), sin embargo, presenta dos anomalías, la primera es que los semáforos peatonales se encuentran desfasados (recorrido $\mathbf{b}_{\mathbf{1}}-\mathbf{C}-\mathbf{b}_{\mathbf{1}}$ ). La segunda (la de mayor riesgo) presenta un camino alterno para su cruce, desafortunadamente esta opción es sumamente peligrosa para el peatón. A continuación, se exhiben algunas de las anomalías detectadas en el camino inseguro; este cruce lo transitan de $\mathbf{D}$ hacia $\mathbf{B}$ y viceversa.

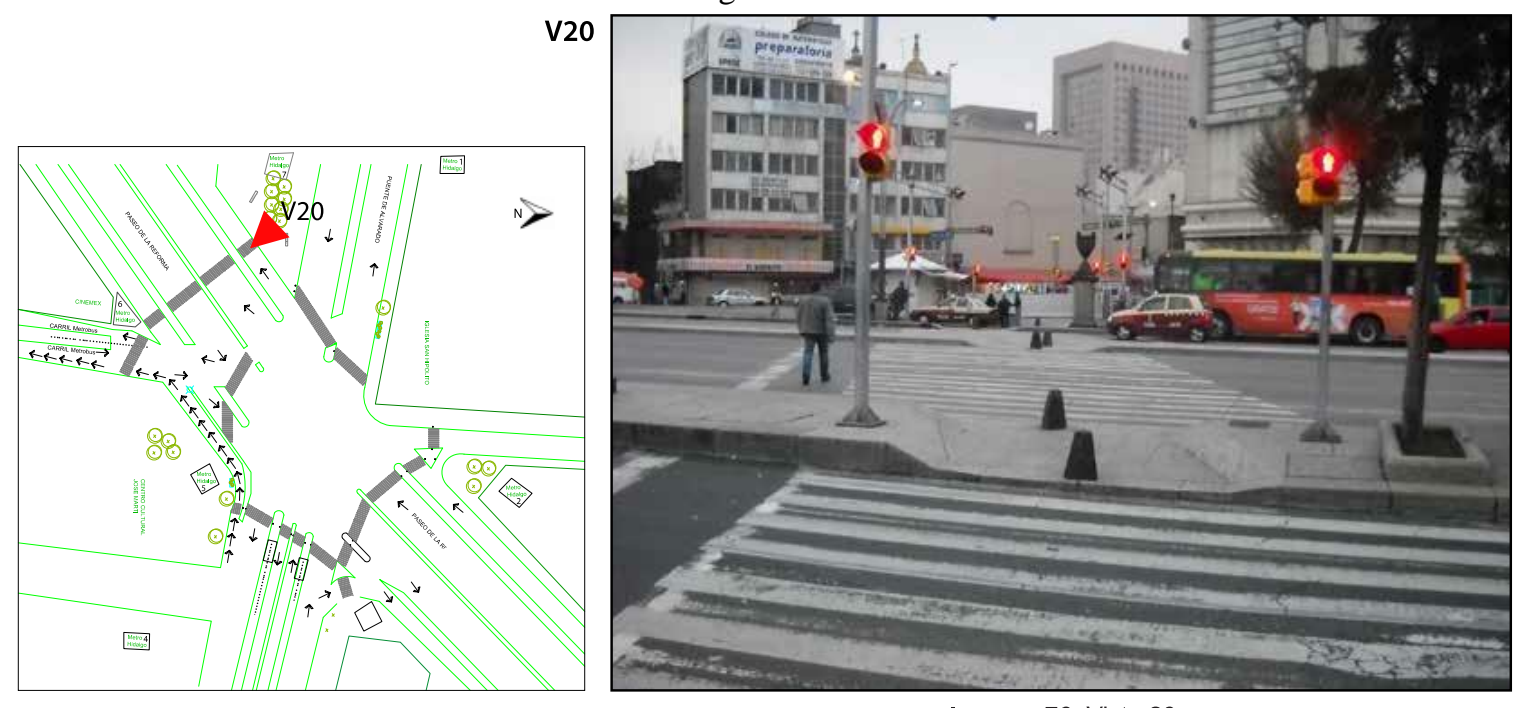

Figura 27

Imagen 76. Vista 20

Cruce seguro Avenida Paseo de la Reforma

Fuente: Santiago Osnaya, 22 de Noviembre 2012, 07:15 am

Figura 28
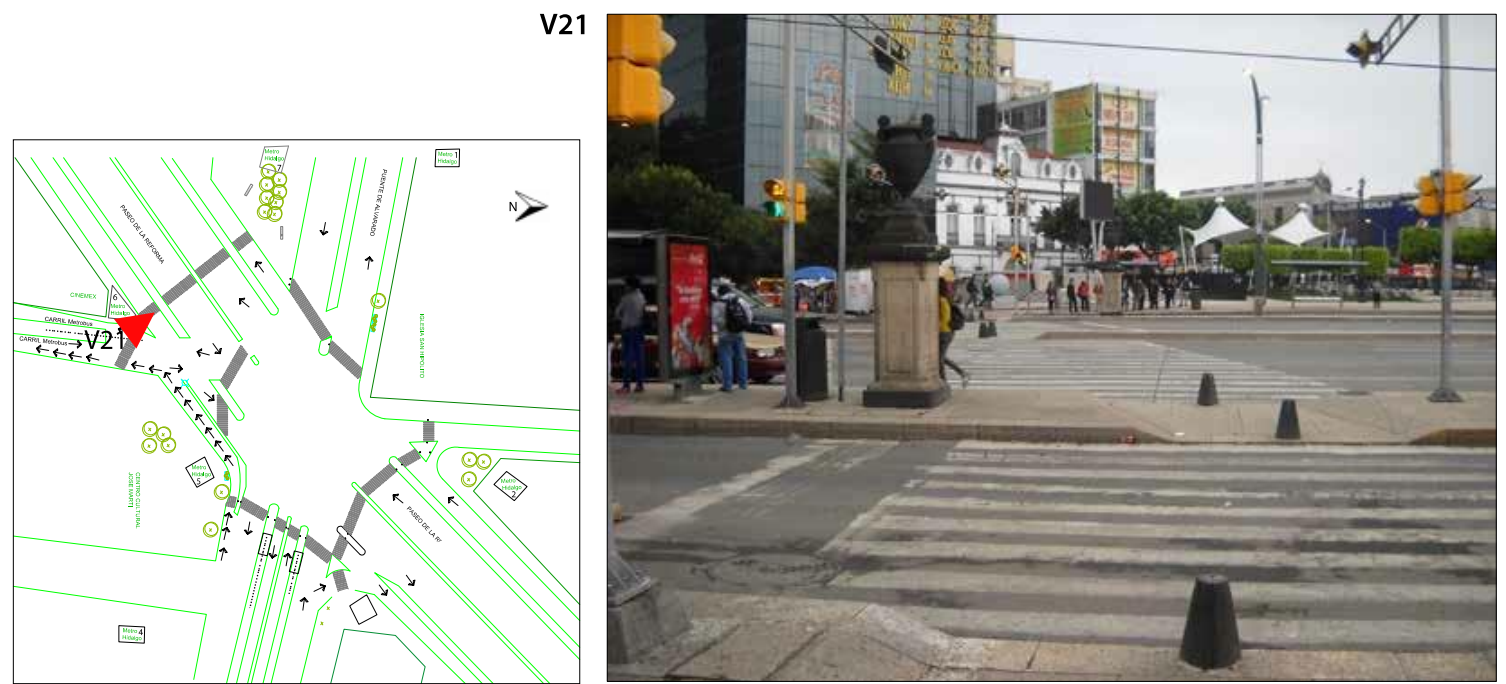

Imagen 77. Vista 21

Cruce seguro Avenida Paseo de la Reforma

Fuente: Santiago Osnaya, 22 de Noviembre 2012, 07:12 am 
El análisis de esta trayectoria (cuadro VIII) denota que es un cruce seguro si se realiza por $\mathbf{b}_{1}$-Cb1, la única anomalía que presenta este camino con relación a la función y aplicación del código vial es la falta de más dispositivos del tipo señal preventiva de peatones.

Cuadro VIII

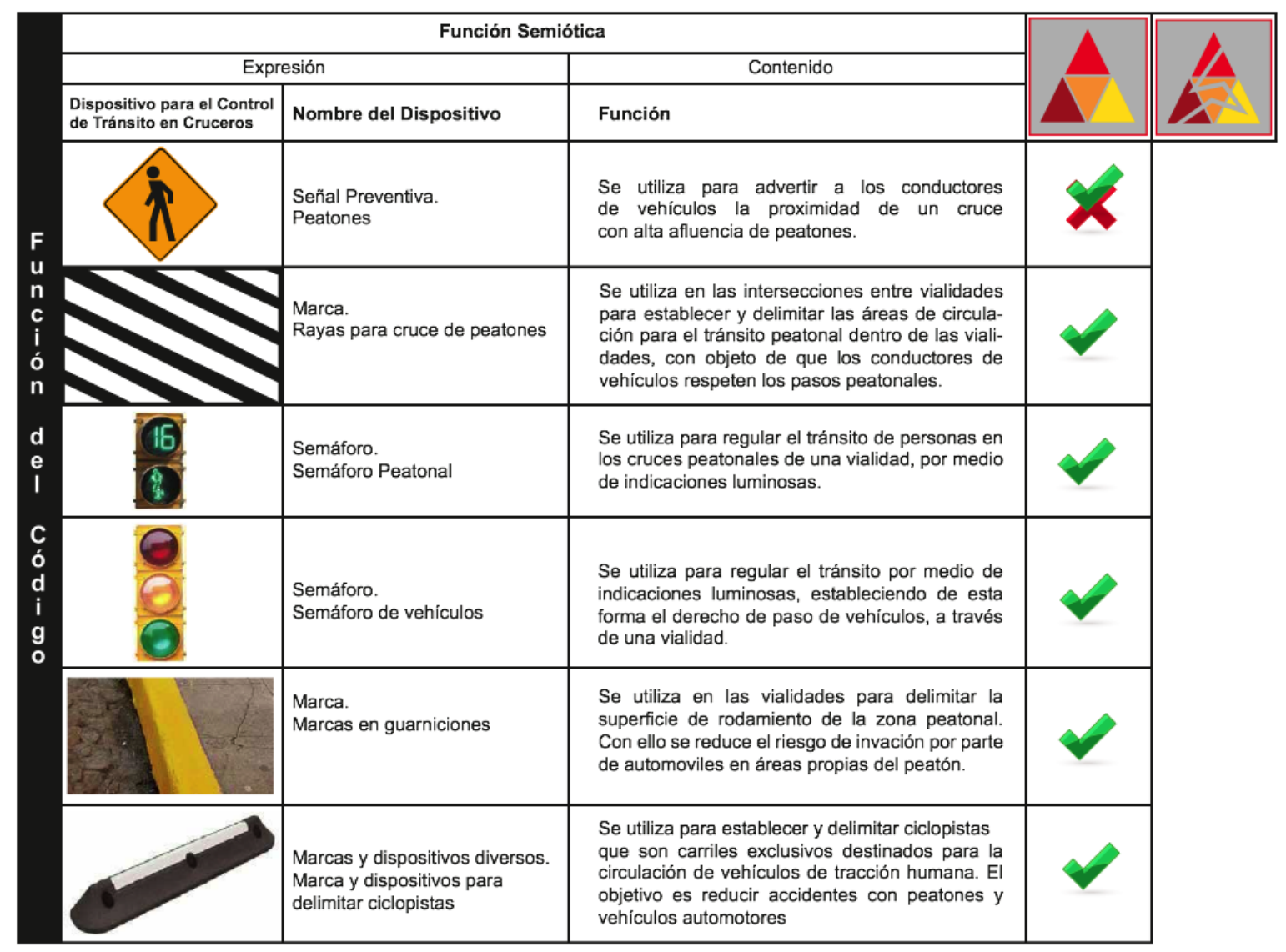

Fuente: Santiago Osnaya, 10/09/2017

A continuación, se exponen algunas situaciones de riesgo que presenta el trayecto B-D-B. Este recorrido no debería de ser utilizado por los peatones, ya que el cruce seguro para atravesar el lado suroeste de la avenida Reforma es el paso b1-C-b1. Sin embargo, la presencia de DCT hacen pensar a los transeúntes que el uso de la trayectoria B-D-B es permitida y segura para pasar la avenida. Las figuras 29 y 30 dan cuenta de cómo la infraestructura, malamente señala el paso peatonal en dicho lugar. 
Figura 29
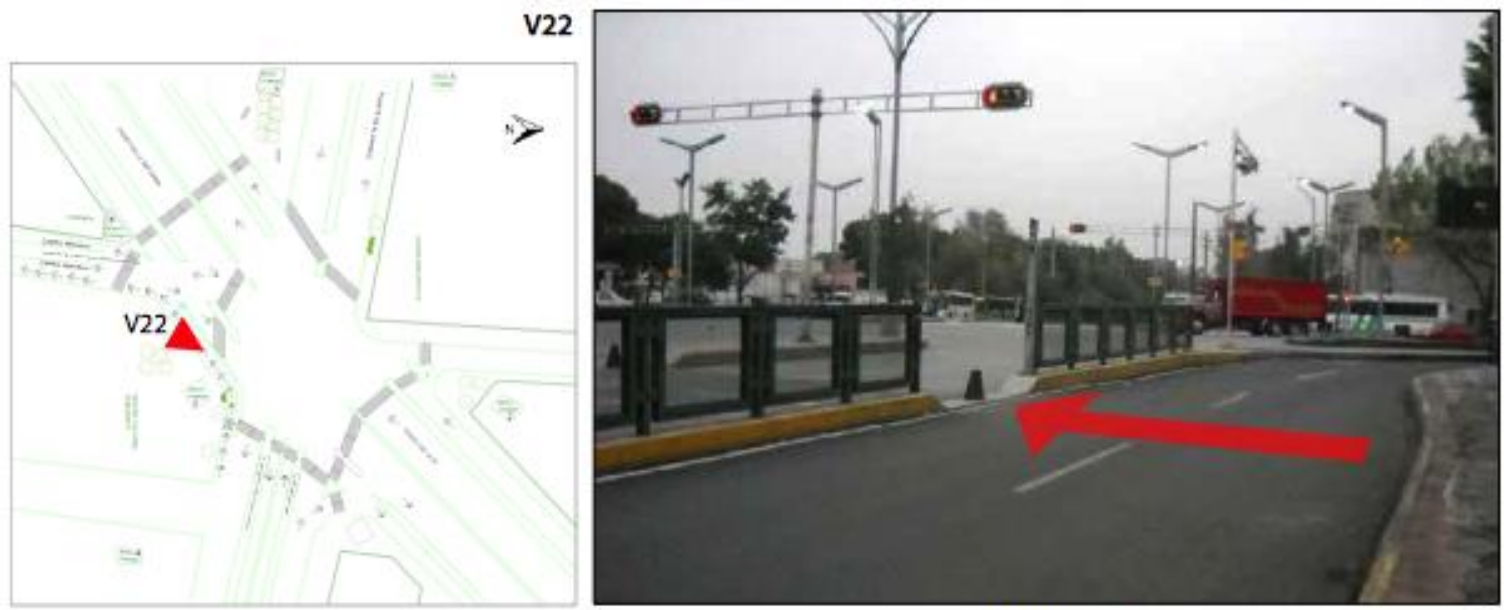

Imagen 78. Vista 22

La infraestructura vial señala cruce de peatones

Fuente: Santiago Osnaya, 22 de Noviembre 2012, 07:10 am

Figura 30
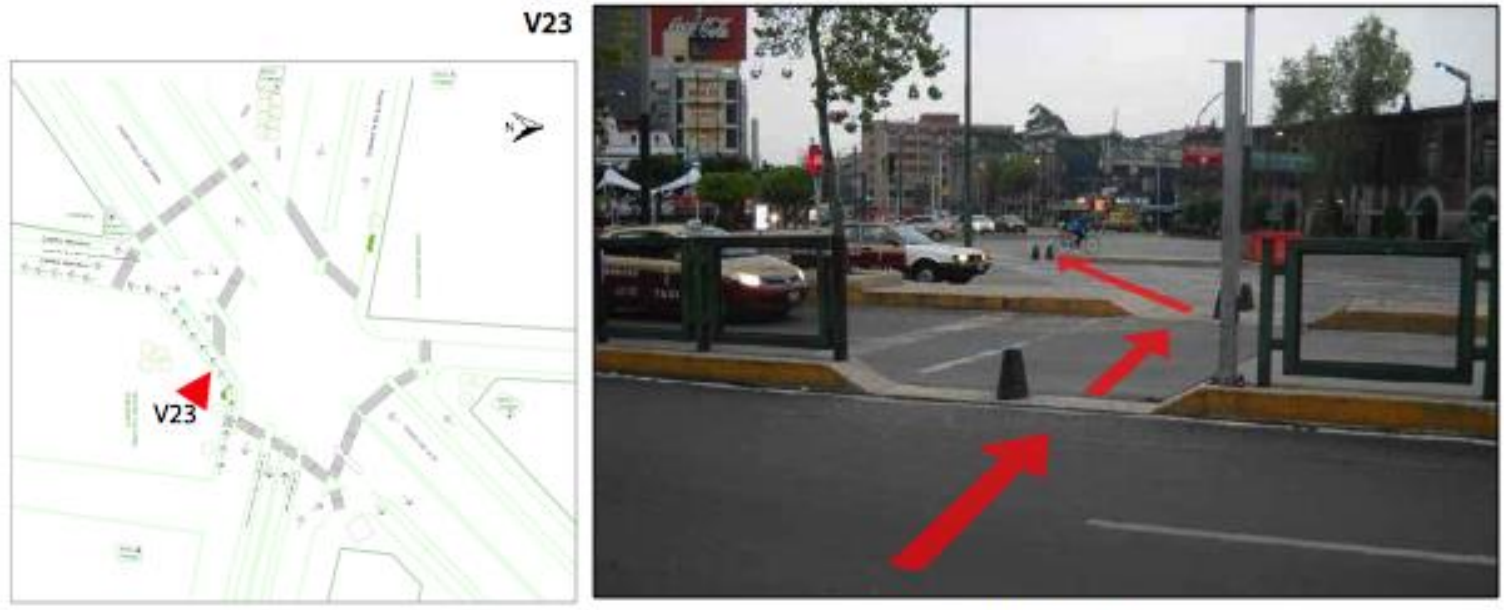

Imagen 79. Vista 23

La infraestructura vial señala cruce de peatones

Fuente: Santiago Osnaya, 22 de Noviembre 2012, 07:15 am

La disfunción que dejan ver las figuras anteriores ( 29 y 30) convierte al trayecto B-D-B en un foco rojo, ya que a partir de la mitad del camino éste adolece de los DCT, los cuales podrían garantizar la seguridad del cruce; al no ser así, los peatones se exponen constantemente al peligro con riesgo de que se produzca un accidente. Además, este crucero tiene mucha afluencia vehicular, de ahí, también, que se incremente la inseguridad de los transeúntes si no utilizan los cruces adecuados. La figura 31, incluso, evidencia la presencia de los oficiales de tránsito, sin embargo, los servidores públicos no alertan del peligro, ni impiden el paso, permanecen indolentes ante la posibilidad de que se genere un siniestro. 
Figura 31
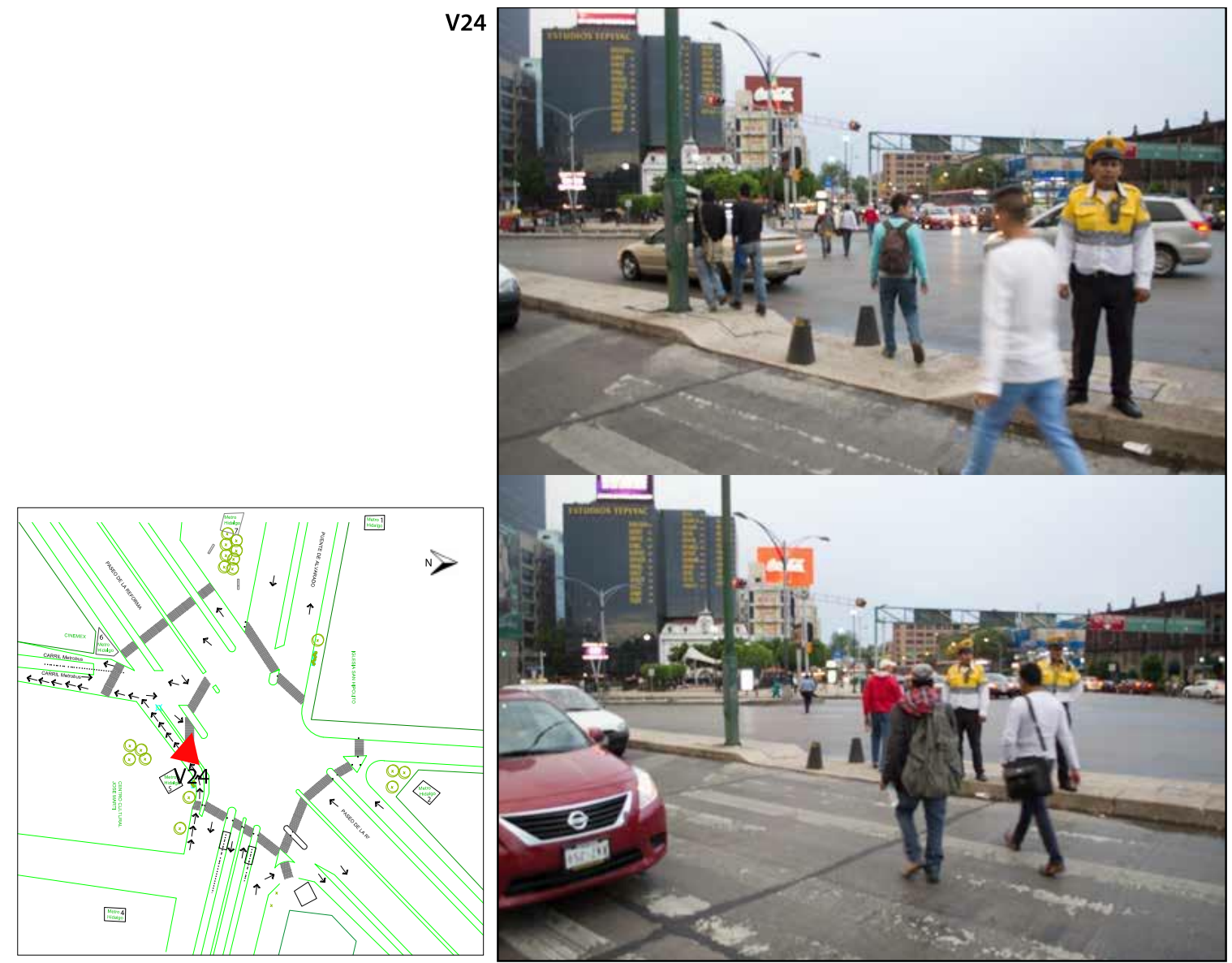

Imagen 80. Vista 24

Oficiales de tránsito no alertan a los peatones sobre el riesgo vial Fuente: Santiago Osnaya, 02 de Abril 2013, 14:05 am

En la siguiente serie de imágenes se demuestra como los transeúntes tienen que esquivar los automóviles para cruzar la avenida, caracterizando a la movilidad de las personas a pie en una situación peligrosa y complicada. El gobierno no ha hecho nada por remover los DCT que generen dichos escenarios, tampoco, han prohibido la movilidad en esta zona. 


\section{Figura 32}

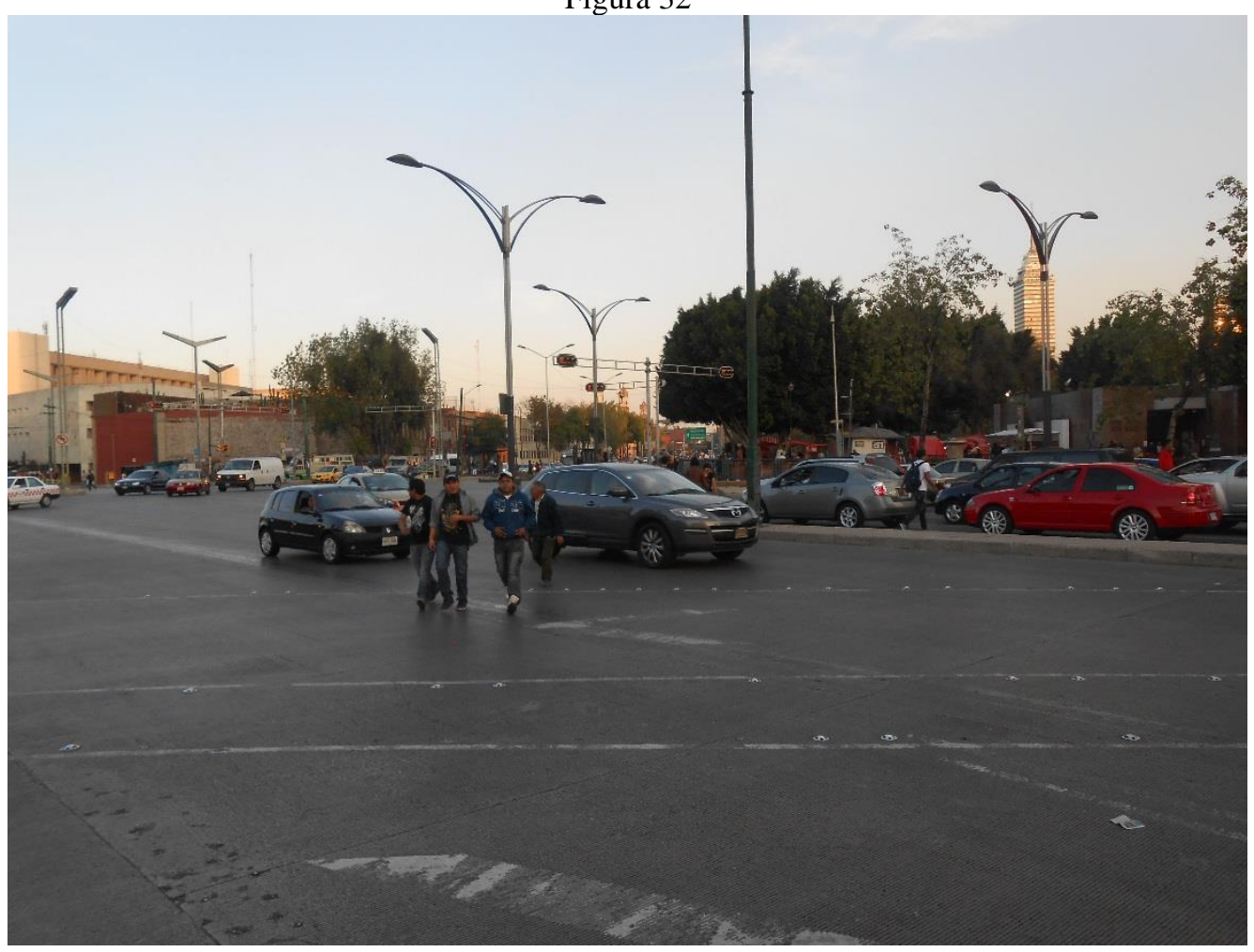

Fuente: Santiago Osnaya, 30 enero 2013, 17:55 pm

Figura 33

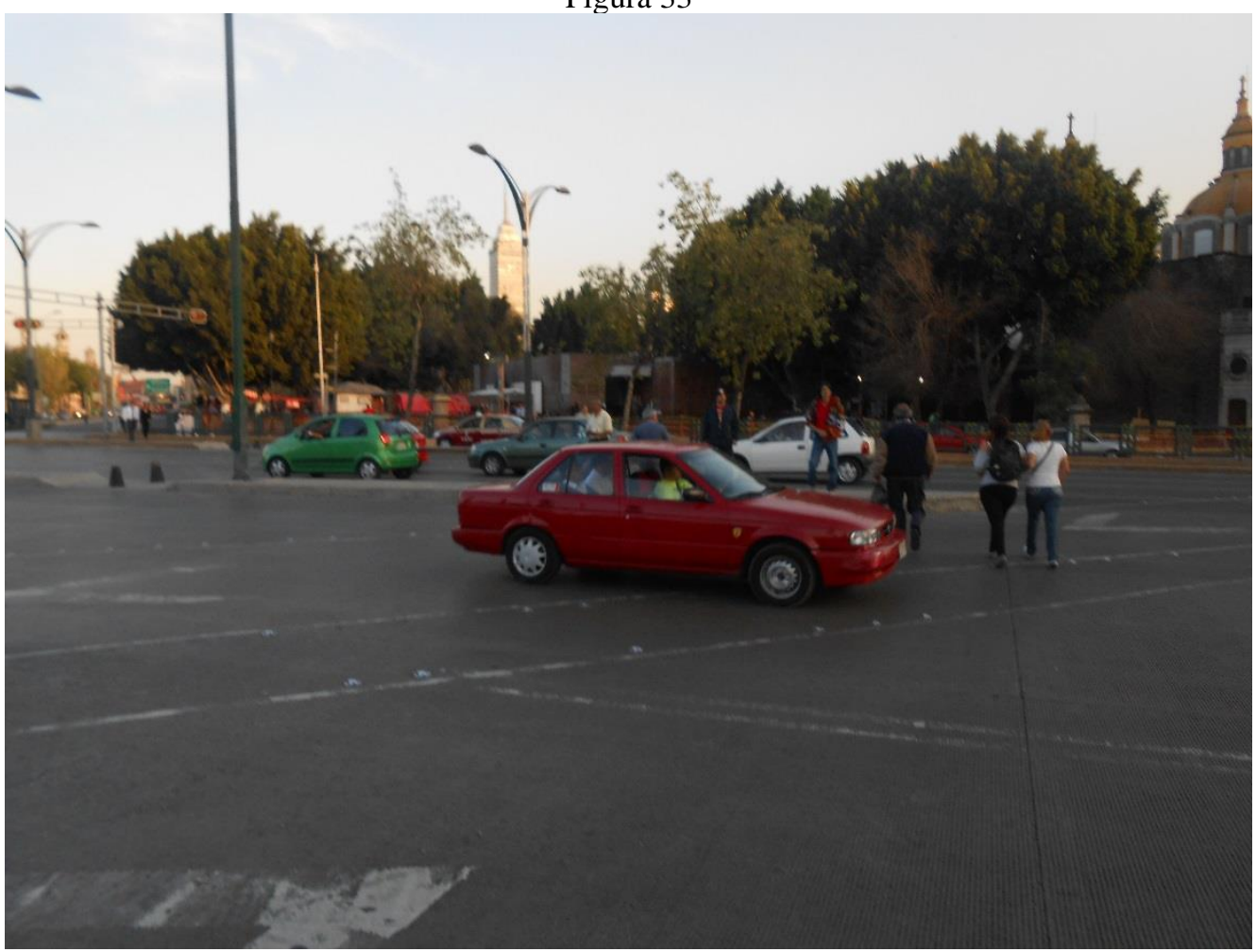

Fuente: Santiago Osnaya, 30 enero 2013, 17:50 pm 


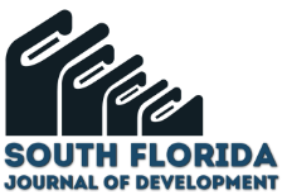

Figura 34

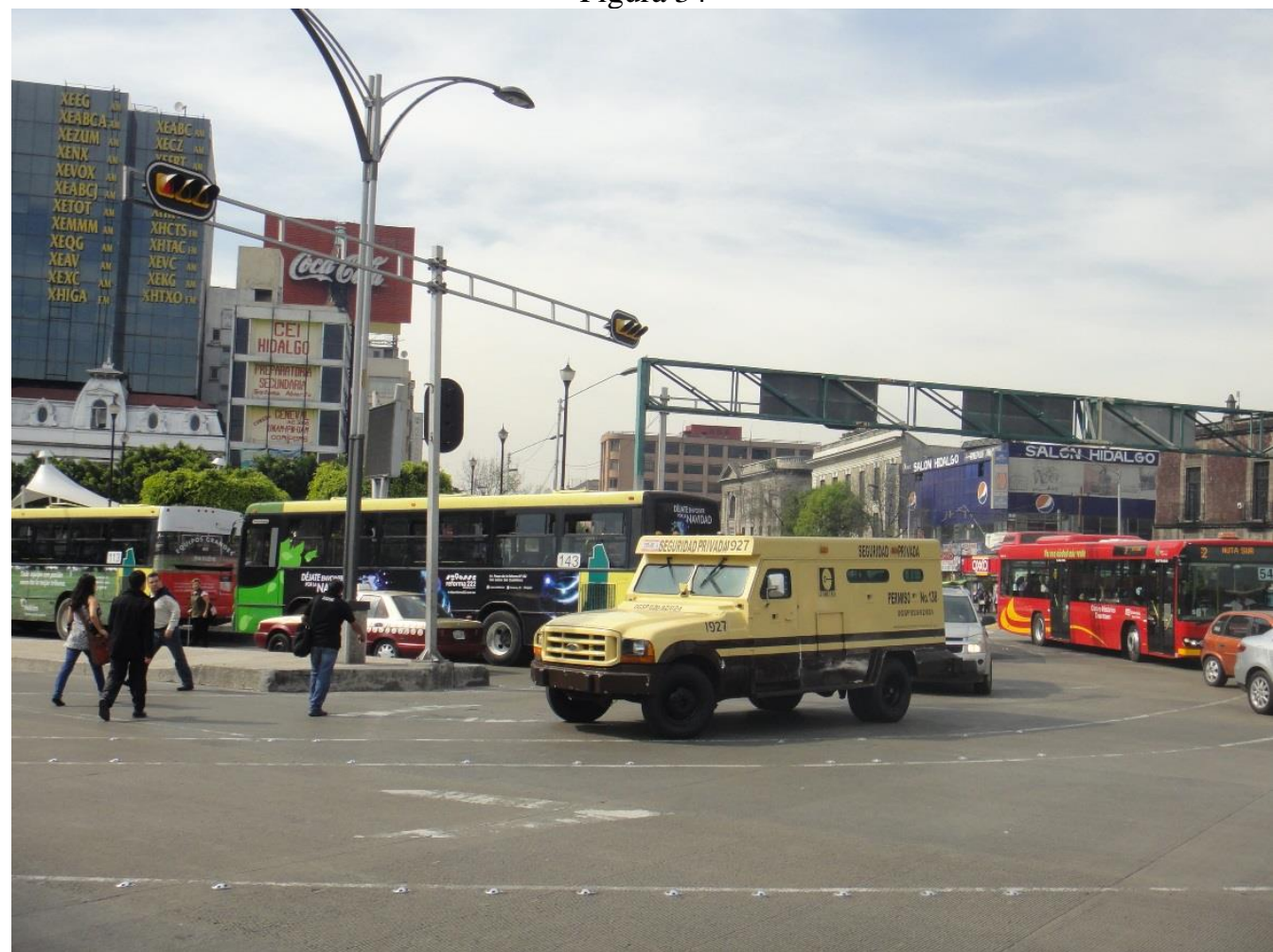

Fuente: Santiago Osnaya, 18 enero 2010, 16:05 pm

Figura 35

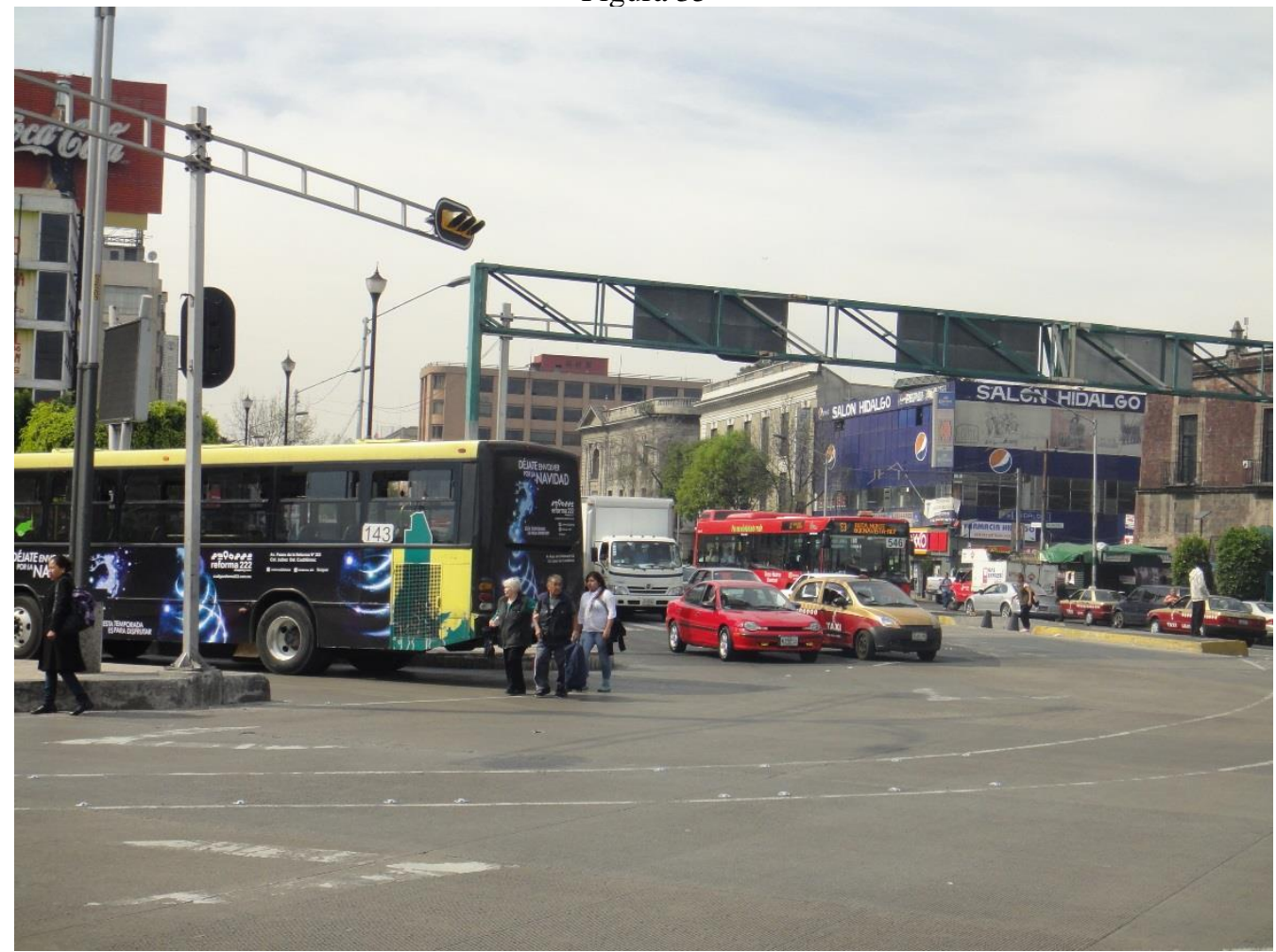

Fuente: Santiago Osnaya, 18 enero 2010, 16:00 pm 
El estudio realizado, permitió evidenciar la falta de señalamientos viales y con ello determinar que los DCT en los cruceros, no están cumpliendo con su función. Esto debido a que dichos dispositivos no son tratados como parte de un sistema de significación. Lo que denota que los funcionarios encargados de la aplicación de los DCT desconocen del uso y función del código vial, así como de la importancia que tiene esta normatividad para la prevención de los accidentes de tránsito. En el apartado siguiente (conclusiones y discusiones finales), se hablará de manera particular acerca de los resultados de la investigación.

\section{CONCLUSIONES Y DISCUSIONES FINALES}

La señalética en la historia de las ciudades ha sido de suma importancia. Desde tiempos remotos los espacios urbanos mostraron la necesidad del uso de signos para poder vivir y desplazarse. En un principio los habitantes se ubicaban y trasladaban de un sitio a otro apoyados de la semántica urbana, posteriormente se desarrollaron signos viales que no solamente apoyaban aspectos de ubicación, sino que, también, normaban la movilidad en los espacios de uso común.

Con la aparición del transporte dio comienzo la construcción de caminos para comunicar unas localidades con otras. De ahí, que los primeros señalamientos viales se hayan implementado inicialmente en las carreteras y posteriormente dentro de las ciudades; esto último debido al crecimiento y los problemas de movilidad al interior de estas. Así, producto de la necesidad de seguridad y regulación del tránsito surge la señalización urbana. Hoy día el código vial es imprescindible en las ciudades, ello se debe a la complejidad de la infraestructura, al gran número de vehículos que circulan por las calles, a la vulnerabilidad del peatón y a la diversidad del transporte. El consumo del espacio físico en medios y velocidades distintas genera conflictos viales y la probabilidad de que sucedan accidentes.

Los últimos reportes de la CONAPRA (2013) registran entre 406508 accidentes anuales a nivel nacional y la Ciudad de México es una de las seis entidades federativas donde se concentra 53\% de ellos. Por esto la importancia de la seguridad para los peatones en las vialidades es vital, cada una de las arterias comunican al usuario con distintos puntos de la ciudad. El uso de dichas vías debería de ser sin riesgos y placentero, sin que se generen angustias o temores al transitarlas. Uno de los factores que propician, en gran medida, una movilidad segura es el código vial, sin embargo, de acuerdo con el estudio presentado esto no sucede, ya que en los sitios donde se llevó a cabo el análisis de la problemática en cuestión fue posible observar su disfunción. En este sentido, si lo que se busca es generar el hábito en las personas de un traslado sin que se presente algún tipo de peligro, tendría que existir un código vial correctamente bien aplicado. 
La propuesta de esta investigación en el campo de la significación es que los dispositivos para el control de tránsito sólo pueden funcionar bien dentro de un sistema de signos. En este texto se propone la sintaxis componencial como única forma de que se genere la función del código vial. Es decir, no puede haber una comprensión semántica del código si todos los signos involucrados en la movilidad y seguridad de los usuarios no están solidariamente dependiendo los unos de los otros. Esto implicaría la no ausencia de alguna señal, su correcta aplicación (en términos espaciales), estado físico, entre otros, lo anterior con el objetivo de procurar el ordenamiento de los movimientos predecibles de tránsito, haciendo de la vialidad un elemento funcional e informativo, así como preventivo para garantizar su seguridad y su operación efectiva del flujo vehicular y peatonal.

El principal objetivo de la investigación es, "identificar en qué medida los dispositivos de tránsito se relacionan con los accidentes viales". Aquí, es pertinente decir que en todos los sitios de estudio se encontraron anomalías en términos de los señalamientos viales. Con ello se demuestra que, para la construcción del significado e interpretación de este, no es suficiente tener señales, ni que éstas se hallen en las calles; se hace necesario que dichos signos se encuentren correctamente aplicados, en buen estado y que funcionen dentro de un complejo sintagmático y solidario generando una interpretación y significado idóneo que posibilite el uso correcto y seguro de los trayectos. De no cumplirse esto, cualquier duda o creencia equívoca del individuo puede propiciar daños irreparables en su constitución física. A este respecto, la investigación permitió identificar cuatro anomalías generales en las intersecciones de estudio en cuanto al código vial:

\section{Cambios diacrónicos de las vialidades y cruceros \\ II. Estructura urbana \\ III. Normatividad \\ IV. Revisión periódica de los DCT}

\section{CAMBIOS DIACRÓNICOS DE LAS VIALIDADES Y CRUCEROS}

Con el transcurrir del tiempo los sitios urbanos están sujetos a cambios y modificaciones. Ello debido a las transformaciones económicas, culturales, políticas y sociales que se generan dentro de la ciudad. La concentración demográfica y su crecimiento natural producen reformas en la estructura de la urbe a través de la creación de viviendas, plazas públicas, centros comerciales, espacios educativos y recreativos, áreas de trabajo, etcétera. De este mismo modo, las vialidades también sufren adecuaciones en respuesta a nuevas necesidades de transporte y movilidad. Saussure (2012) escribe que lo diacrónico está relacionado con la evolución del lenguaje en el transcurso del tiempo; de manera análoga es posible 
observar históricamente cómo las trayectorias vehiculares sufren transformaciones, lo que hace necesario pensar en dos complicaciones necesarias de resolver. La primera tiene que ver con la complejidad del código vial, pues a raíz de que una vía cubre nuevas exigencias de traslado (Metrobús y ciclovías), se hace forzoso pensar en la aplicación de nuevos dispositivos que ayuden a la comprensión y el uso de las vialidades por parte de conductores, peatones, ciclistas, entre otros.

Lo problemático de dicha situación es que a medida que se incorporan caminos para medios de transporte distintos a los automóviles, el número de señalamientos se incrementa. Esto genera que el usuario tenga que decodificar una mayor cantidad de signos para cruzar una avenida, provocando angustia y confusión en las personas.

\section{ESTRUCTURA URBANA}

Los principales elementos que conforman los cruceros viales en términos estructurales son los siguientes: banqueta, arroyo vehicular, guarniciones, drenaje pluvial, sistema de alumbrado, dispositivos para el control de tránsito, vegetación, rampas, etcétera. Cada uno de estos componentes sufre cambios con relativa frecuencia, debido a modificaciones, reparaciones, envejecimiento, daños causados por la interacción de los usuarios y por las condiciones climatológicas. Por ejemplo, debido a la ubicación geográfica de la Ciudad de México, ésta resulta afectada por el fenómeno de las lluvias durante el periodo de otoño y verano principalmente. A causa de esto, el asfalto de las avenidas en la época de mayores precipitaciones sufre deterioro, ya que se forman agujeros (mejor conocidos como baches) en la superficie de rodamiento. Esta clase de desperfectos son remediadas por las autoridades correspondientes, sin embargo, en la mayoría de los casos estas reparaciones no contemplan el arreglo de los DCT.

La figura 36 es una clara muestra de esta situación que produce un conflicto en la interpretación por parte del usuario. 
Figura 36

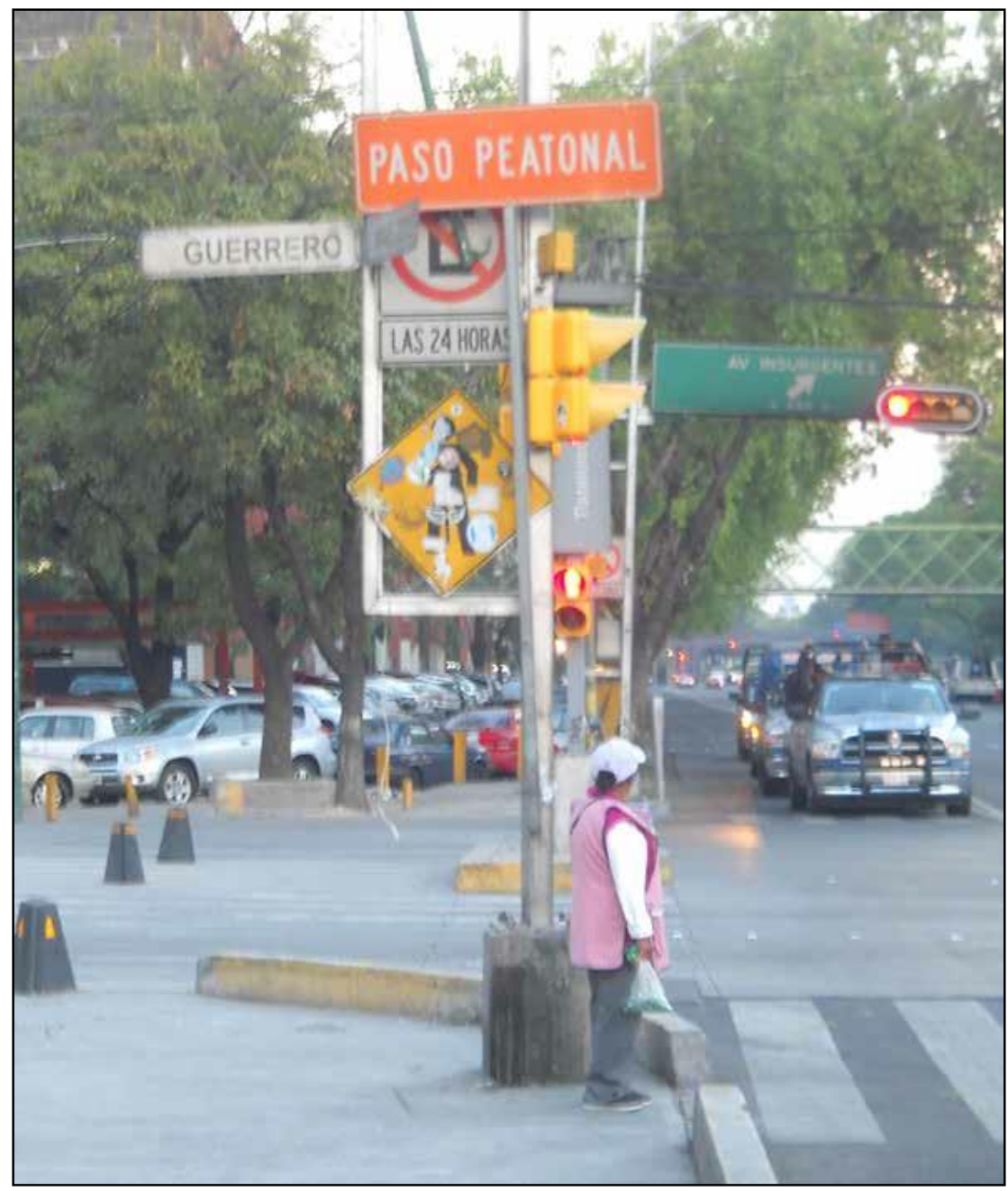

Fuente: Santiago Osnaya, 30-abril-2012, 6:15 pm

El contexto de la problemática que se menciona en el párrafo anterior fue una recurrencia que se encontró en los tres casos de estudio. Por ejemplo, en el estudio que aquí se muestra (III) las modificaciones realizadas para el funcionamiento de las líneas 4 y 3 del Metrobús ${ }^{2}$ no se contempló remover la señalización que funcionaba antes del cambio. Esta situación genera que existan una duplicidad de mensajes en la intersección. De ahí que las personas elijen e interpretan en relación con su hábito, comodidad y necesidad. Pero la existencia de ambos códigos (Av. Tacuba en su lado este) genera riesgo en los peatones que aún utilizan el sistema de señalización antiguo, ya que, no existen las condiciones para que el trayecto sea seguro.

\footnotetext{
${ }^{2}$ Las rutas 3 y 4 del Metrobús de la Ciudad de México comenzaron a dar servicio el año 2011 y 2012 respectivamente.
} 


\section{NORMATIVIDAD}

Las leyes relacionadas con los DCT son muy anticuadas. El Manual de dispositivos para el control de tránsito en áreas urbanas y suburbanas del Distrito Federal (ahora Ciudad de México) fue publicado por el Gobierno del Distrito Federal en año 2001. Es decir, tiene más de quince años, sin que se haya actualizado. De ahí que se haga necesaria su revisión, pues las normas deben ajustarse a los escenarios actuales. Existen señalamientos creados por las presentes necesidades de movilidad en la ciudad, sin embargo, estos nuevos dispositivos no tienen una autorización legal para ser empleados. Por ejemplo, el MDCTAUSDF no contempla el uso de semáforos para bicicletas e incluso el gobierno de la Ciudad de México utiliza las marcas para delimitar a las ciclopistas de color verde siendo que la norma de dicho manual (2001, p. 269) indica que deben aplicarse en tono blanco. Ni que decir de los nuevos sistemas de transporte público, como es el caso del Metrobús, el cual maneja señalamientos que tampoco están normados jurídicamente por las instancias correspondientes.

Otra situación de la vigencia normativa son aquellos casos de DCT que ya no tienen vigor de acuerdo con la reglamentación actual, es decir, se utilizan dispositivos que no han sido reemplazados de acuerdo con las nuevas políticas públicas y por lo tanto carecen de toda validez. Esta es una problemática constante en las vialidades: la falta de actualización y remoción de los señalamientos que ya han prescrito.

Así, cada vez que un nuevo manual se aprueba y se publica es porque detrás existen estudios y acuerdos internacionales que justifican el uso y la efectividad de las nuevas señales. A este respecto el MDCTAUSDF nos dice que un DCT debe cumplir con seis requisitos primordiales: proporcionar seguridad, llamar la atención, transmitir un mensaje sencillo y claro, hacer que se respete, estar ubicado de tal modo que permita al usuario recibir el mensaje y estar localizado de manera que las personas cuenten con el tiempo necesario para que reaccionen efectivamente y puedan tomar una decisión oportuna. Por estas razones se debe dar importancia a la actualización del código vial.

\section{REVISIÓN PERIÓDICA DE LOS DCT}

Otra de las inconsistencias recurrentes es el estado de los dispositivos in situ. La investigación permitió constatar que algunos de ellos no existen, otros más se encuentran deteriorados por el ambiente (ruido natural) o producto de la mano del hombre (ruido artificial). Esto ocurre simplemente porque no existe un programa de vigilancia continuo para verificar el estado actual de los señalamientos viales.

Las cuatro irregularidades comentadas afectan al sistema de significación del código vial, ya que, si alguno de los signos se desliga sintagmáticamente de los demás dentro de la cadena de significantes, la función de este sistema de reglas se interrumpe al generar estados de incertidumbre en los usuarios provocando situaciones inseguras y accidentes en las vialidades. 
En los párrafos anteriores, se evidencia que el propósito de esta investigación fue tratar de comprender la problemática con el objetivo de tomar decisiones en torno al correcto uso y aplicación de los dispositivos de tránsito. Esto para mejorar la situación anómala en los cruceros viales. De ahí que el valor de la información obtenida sirvió para saber qué relación que existe entre los accidentes y los signos viales, e instrumentar tareas que prevengan cruceros inseguros, así como descartar los DCT como factor de riesgo en los siniestros de tránsito. El presente estudio pretende servir como recomendación a los funcionarios correspondientes, en beneficio de todos los actores que utilizamos las vialidades para tratar de reducir el índice de riesgos.

Así, los resultados de esta indagación proporcionan información para generar un punto de vista diferente con relación a la aplicación de los DCT que permita mejorar la prevención de accidentes y tener efectos positivos, así como generar cambios en las políticas públicas concernientes a esta materia. 


\section{BIBLIOGRAFÍA}

Borah, W., (1974) Ensayos sobre el desarrollo urbano en México, México, Secretaría de Educación Pública.

Conapra (2013) “Tercer informe sobre la situación de la seguridad vial” Obtenido el 02 de diciembre del 2013, de

http://conapra.salud.gob.mx/Interior/Documentos/Observatorio/3erInforme_Ver_ImpresionWeb.pdf Eco, U., (1997) Kant y el ornitorrinco. Barcelona, Lumen.

Gobierno del Distrito Federal, (2001) Manual de dispositivos para el control de tránsito en áreas urbanas y suburbanas. México, Gobierno del Distrito Federal.

Hjelmslev, L., (1971) Prolegómenos a una teoría del lenguaje. Madrid, Gredos.

Osnaya, S., (2020) Signos urbanos. Un enfoque semiótico de la relación entre las señales y los accidentes viales, México, AM Editores.

, (2019) "Una aproximación semiótica para la interpretación del código vial" en Sociosemiótica y cultura. Principios de semiótica y modelos de análisis. Ciudad de México, México, Instituto de Investigaciones Sociales UNAM.

Saussure, F., (2012) Curso de lingüística general. Argentina, Losada.

Who (2011) Decenio de acción para la seguridad vial. Obtenido el 24 de enero del 2013, de https://www.who.int/roadsafety/decade_of_action/es/ 